آراء هدراء المدارس في همافظة اربد نهو أهمية توظيف تكنولوجيا

المعلومات والاتهالات في التعليم وأهم العقبات التي تواجههم لتهم

\title{
I I I
}

د. بسام فايز حمد السمكي

أستاذ مساعد جامعة أم القرى - الكلية الجامعية للبنات بالقتفذة

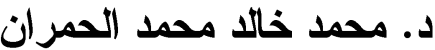

أستاذ مساعد جامعة البلقاء التطيقية -كلية الحصن الجامعية

هدفت هذه الاراسـة إلى التعرف على آراء مدراء المدارس في محافظة اربد نحو أهمية استخذام

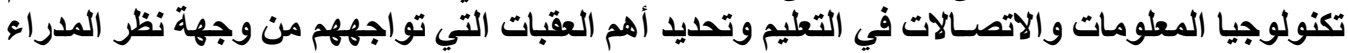

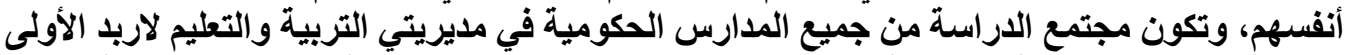

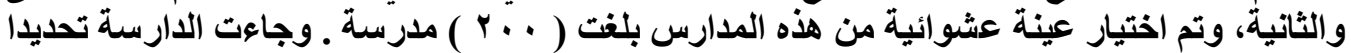

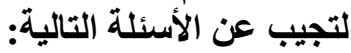

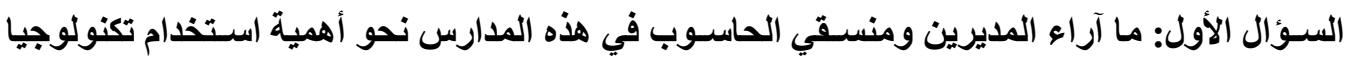

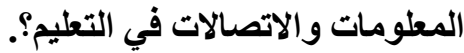

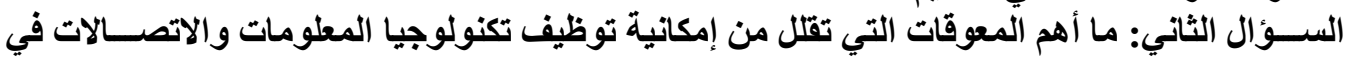

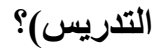

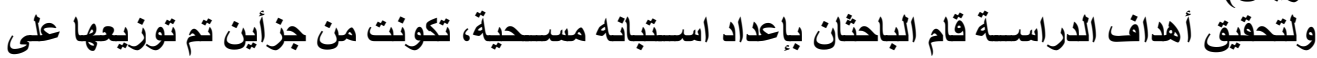

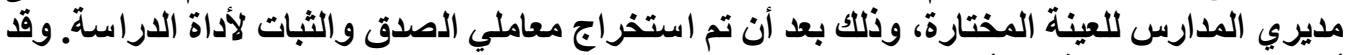

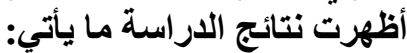

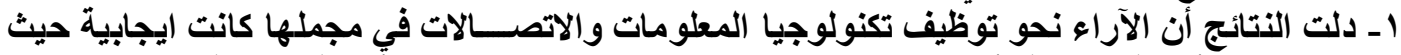

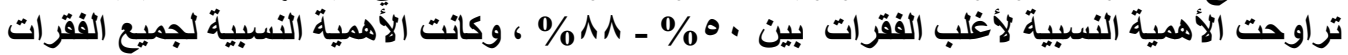

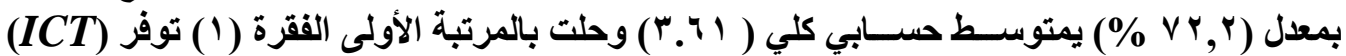

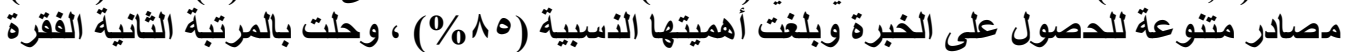

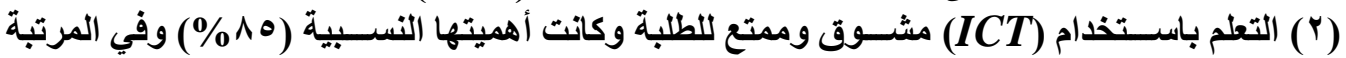

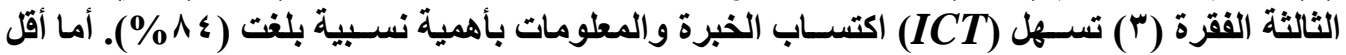

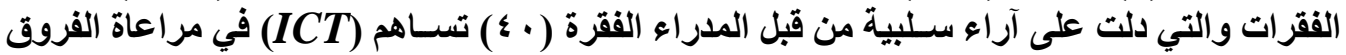

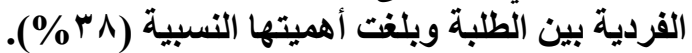

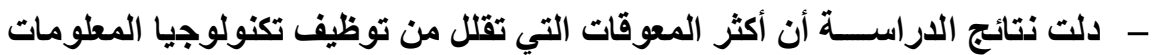

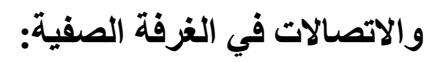

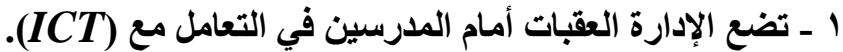
r ـ الإدارة الددرسية غير قادرة على توظيف (ICT) في العمليات الإدارية. 


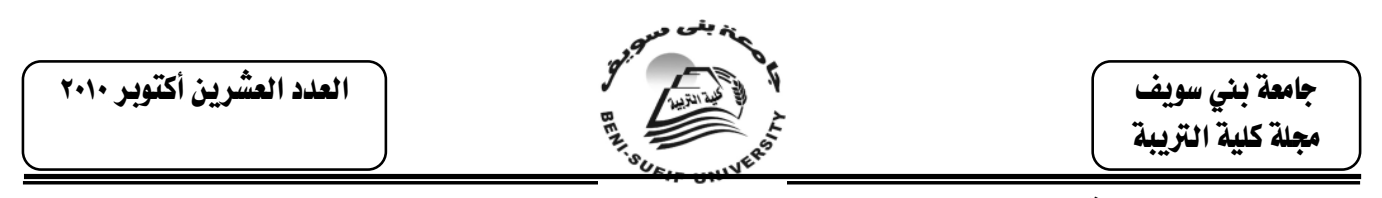

ب - الإدارة المدرسية لا تثجع استخدام (ICT).

HEADMASTERS OPINIONS IN IRBID GOVERNORATE ABOUT THE

IMPORTANCE OF USING INFORMATION AND COMUNICATION

TECHNOLOGY IN FIELD OF EDUCATION AND THE OBSTACLES THAT HINDER THEM.

\section{By \\ Mohammed Al-Homran \& BASSAM AL-SAMAKI}

\section{ABSTRACT}

This study aims at shedding light on headmasters opinions in Irbid Governorate about the importance of using information and communication Technology in field of education and pinpoint the major obstacles that hinder them.

The study sample consisted of all the public schools in Irbid first and second educational directorate. Total number of these random schools is 200 schools.

The study specifically answers the following questions:-

1- Opinions of school masters and computer coordinators in these schools regarding the importance of using (ICT) in the field of education.

2- What are the most important obstacles that hinder the use of (ICT) in discovery schools?

The results of the study revealed the following aspects:-

1- Attitudes towards (ICT) system were quite positive. The average importance of most articles was $50 \%-80 \%$. The average importance of all articles was $72,2 \%$ with an average of 3.61. Article (1) (ICT) provides different sources to obtain experience and experience $85 \%$. Article (2) which states that the use of (ICT) system is quite exciting and interesting for students has the same importance $(85 \%)$. Then, there's article number (3) which states that the use of (ICT) system facilitates acquisition of experience and information (84\%).

Finally, the least important article with negative opinions of masters was article (40) which states that (ICT) takes individual differences into consideration $(38 \%)$.

2- Results of the study indicated that there are major obstacles hindering the application of (ICT) system in classrooms. These are:1- Management put obstacles face to face with teachers in dealing with (ICT) system.

2- School management is unable to use (ICT) in managerial processes. 


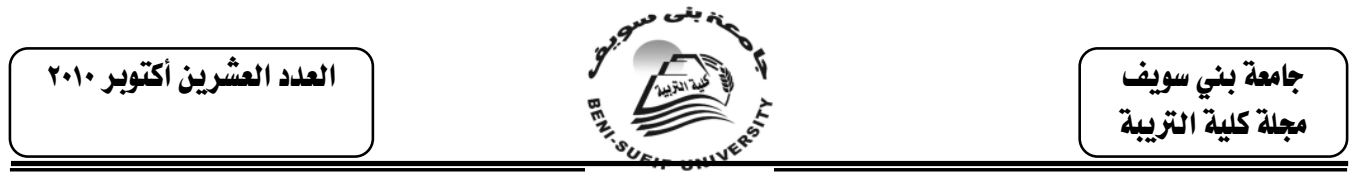

3- School management doesn't encourage the use of (ICT).

\section{آراء هدراء المدارس في هحافظة اربد نهو أهمية توظيف تكنولوجيا المعلومات والاتصالات في التعليم وأهم العقبات التي تواجههم}

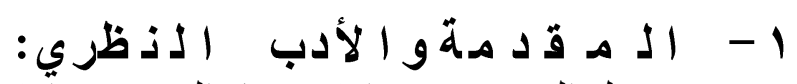

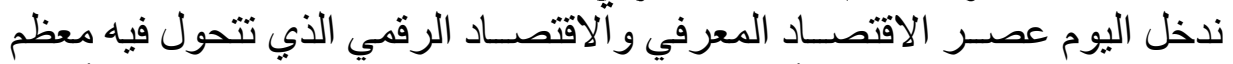

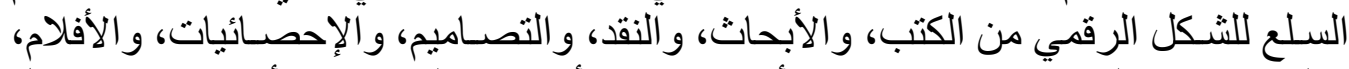

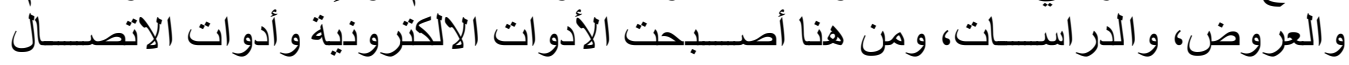

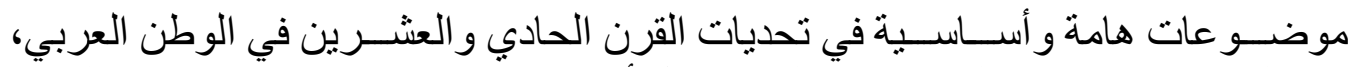

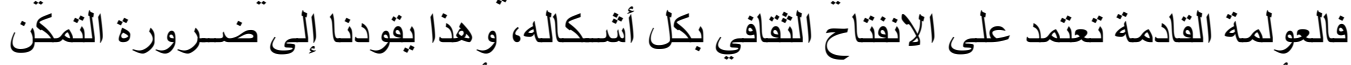

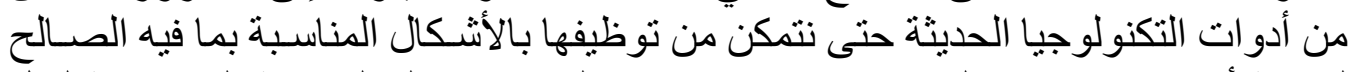

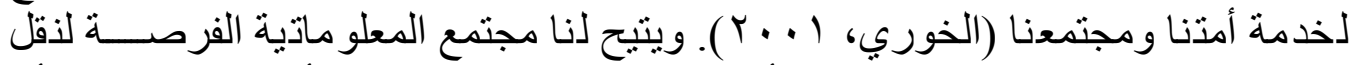

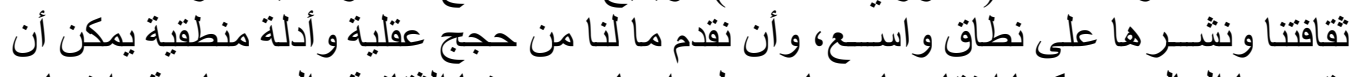

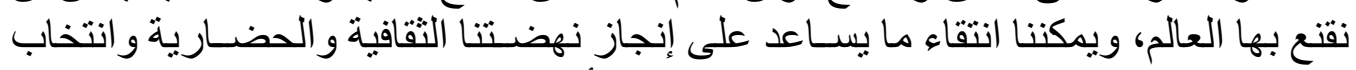

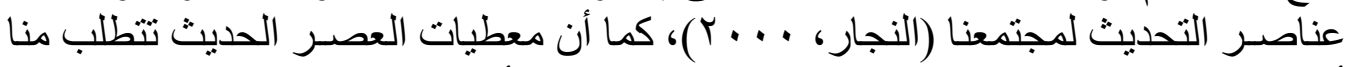

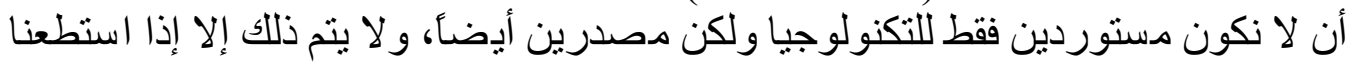

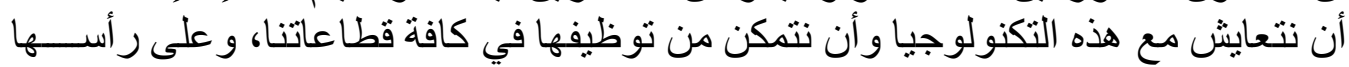

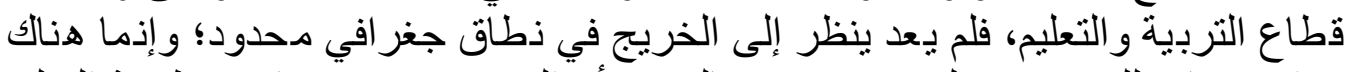

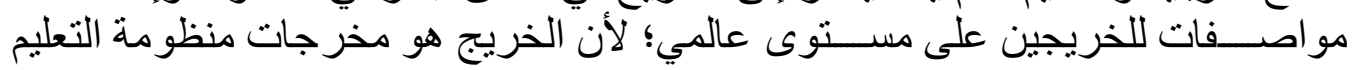

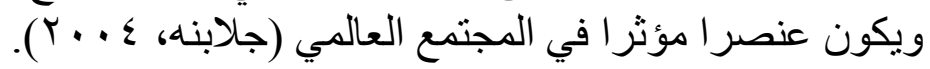

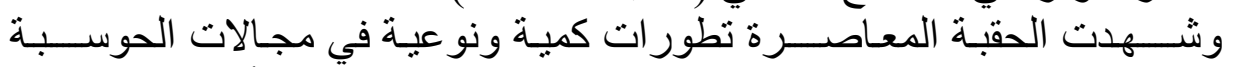

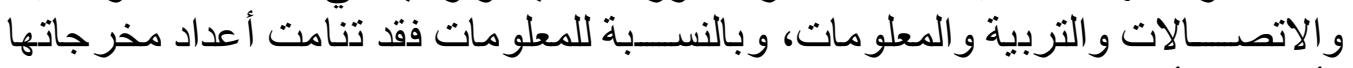

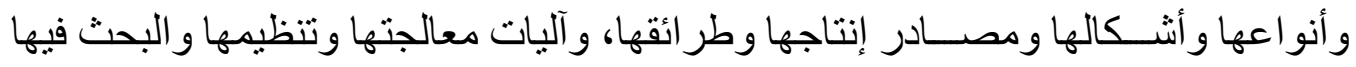

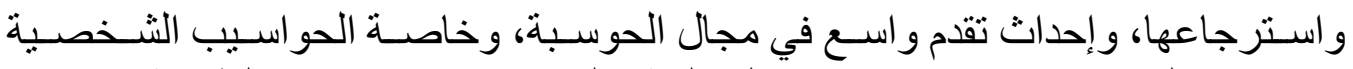

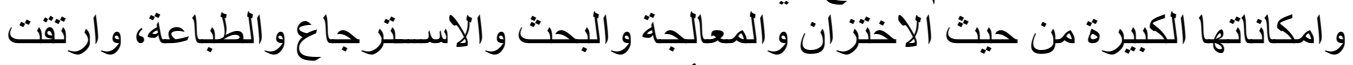

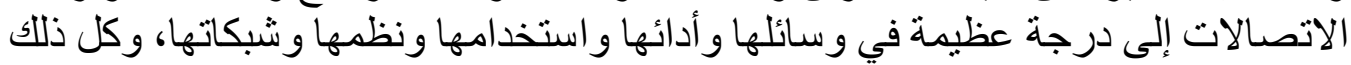

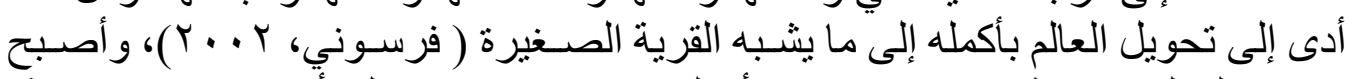

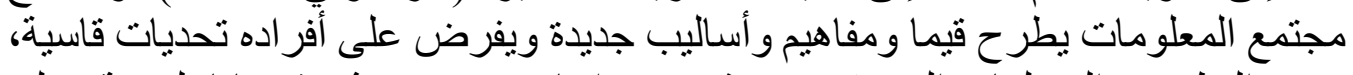

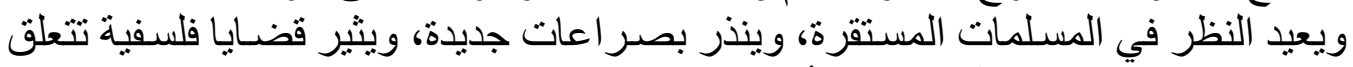

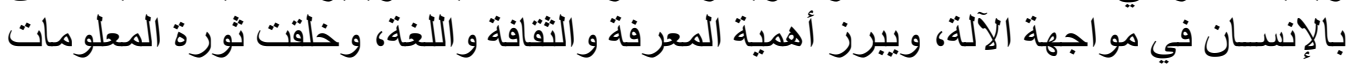

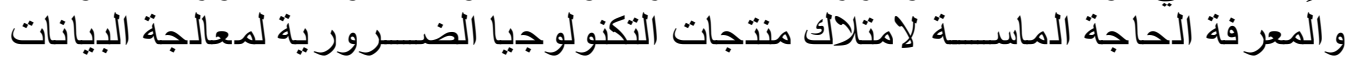

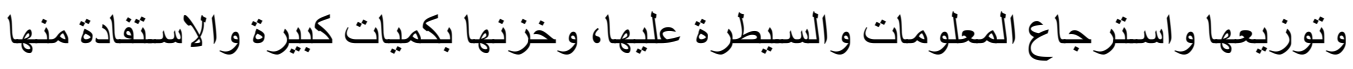


كمورد مهم من موارد الحصـول على المعرفة و الخبرة، والمورد الأهم للقطاعات التعليمية و التربوية (Barry, 1996).

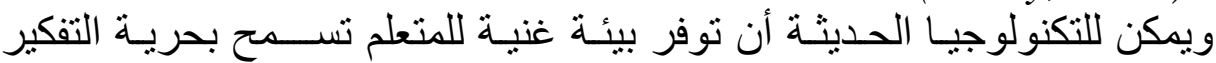

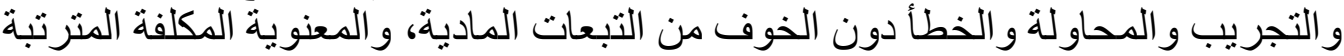

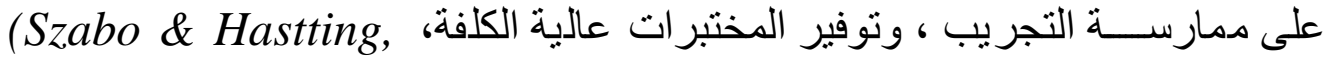

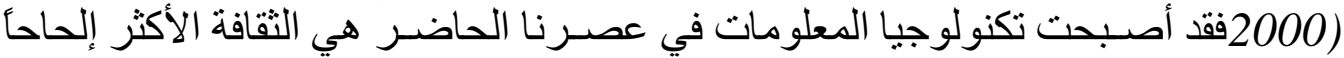

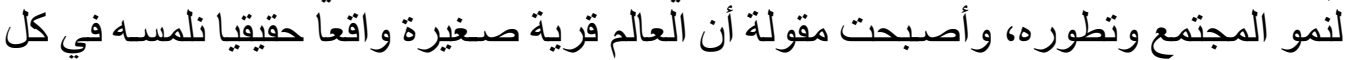

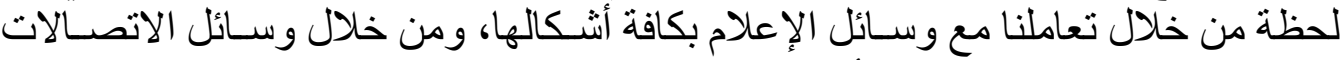

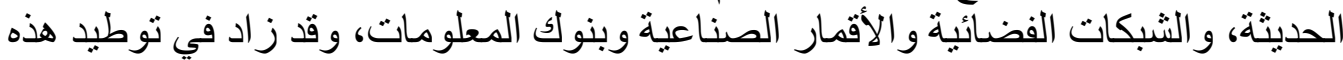

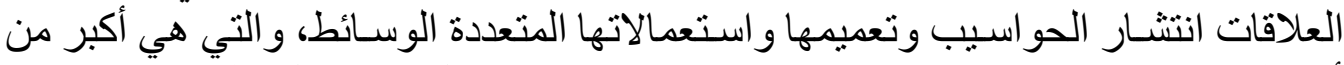

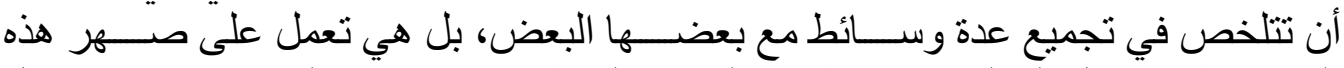

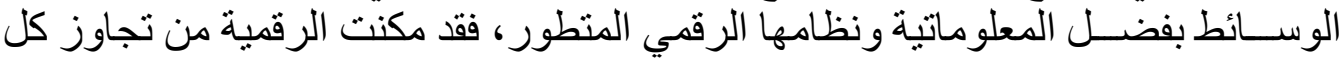

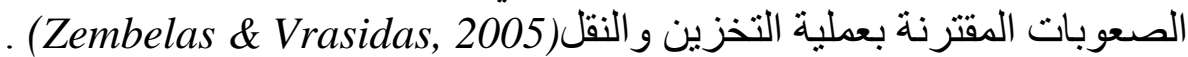

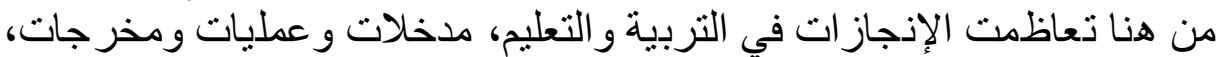

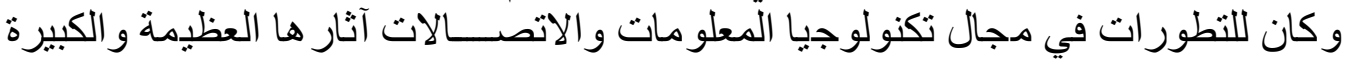

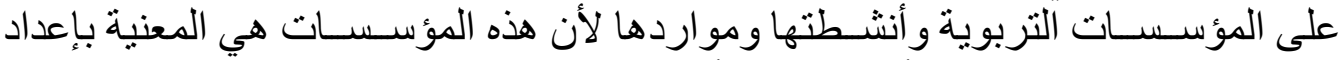

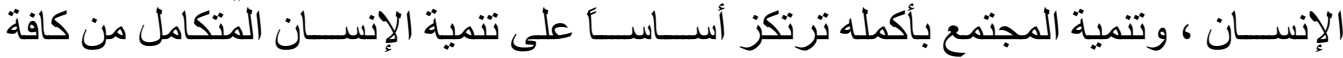

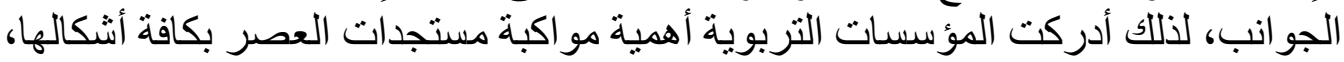

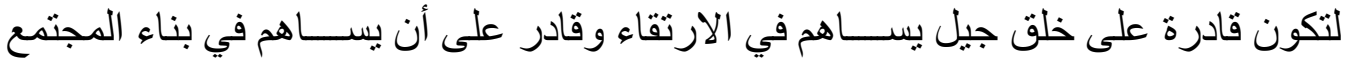

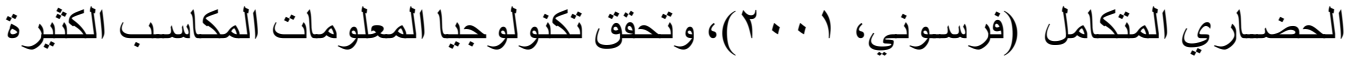

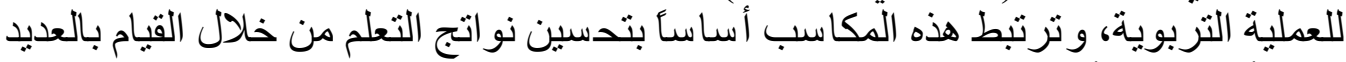

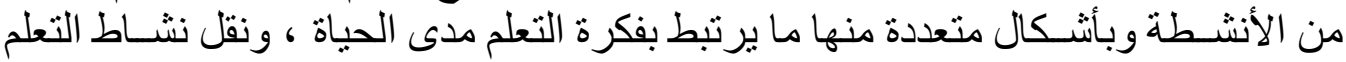

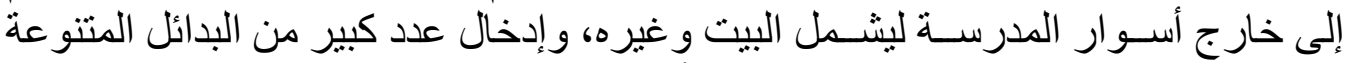

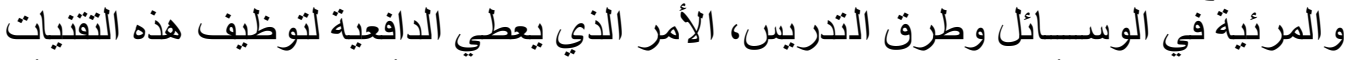

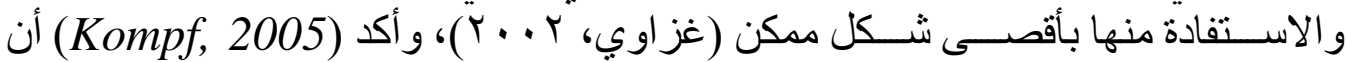

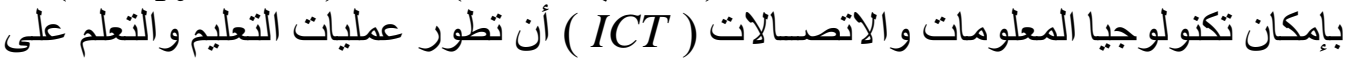

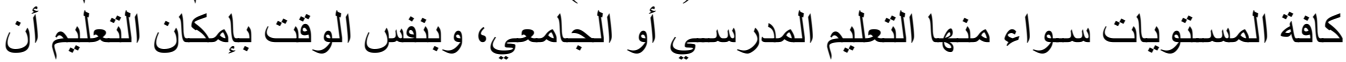

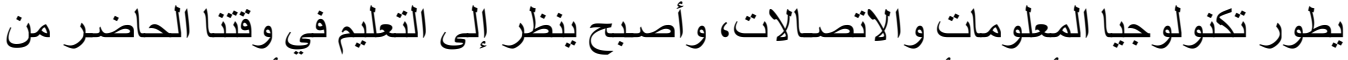

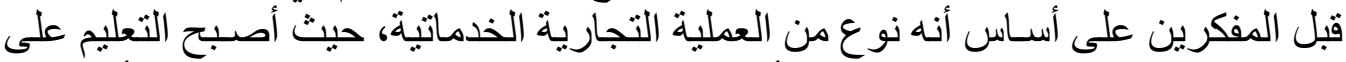

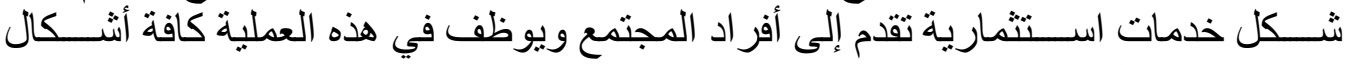

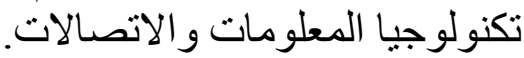

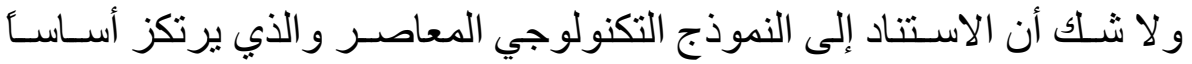

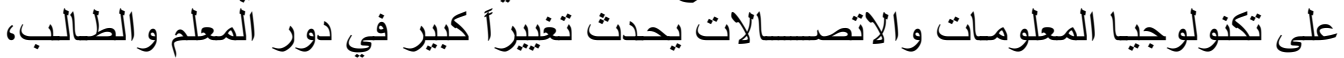

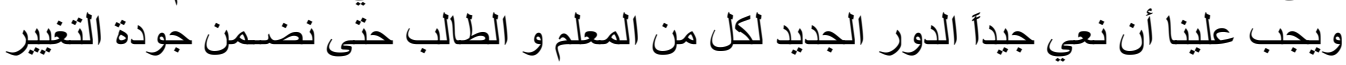


و الارتقاء، وأن يتم ذلك من خلال تشـكيل الوعي و القناعة بجميع القائمين على هذه العملية وخصوصـا المعلم والطالب.

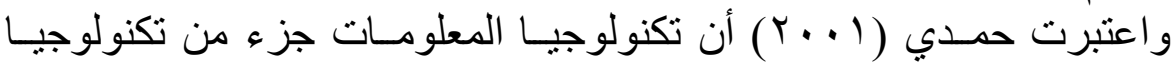

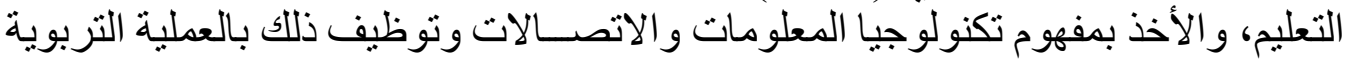

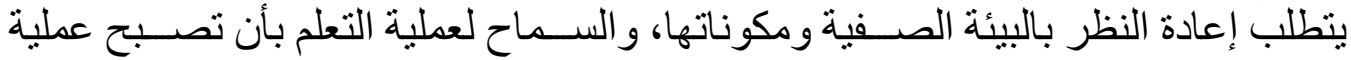

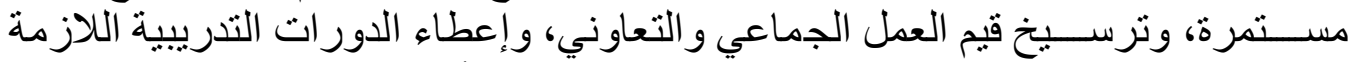

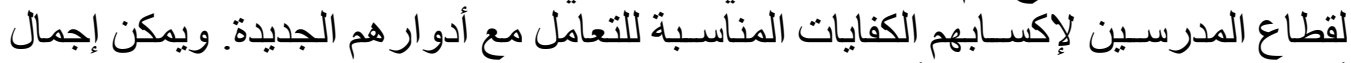

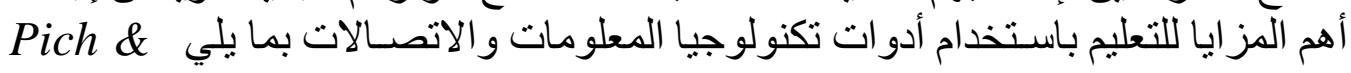

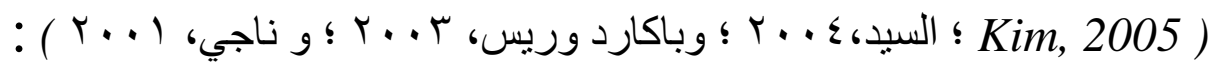

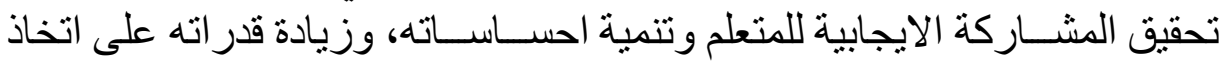

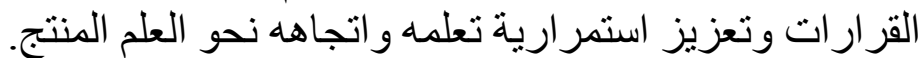

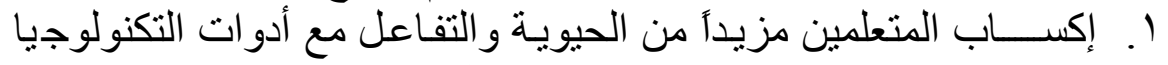

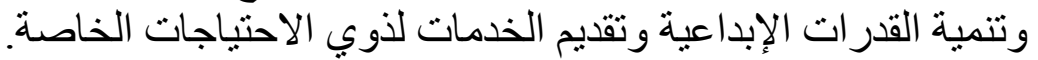

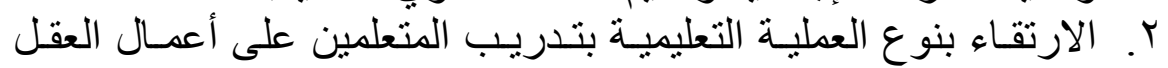

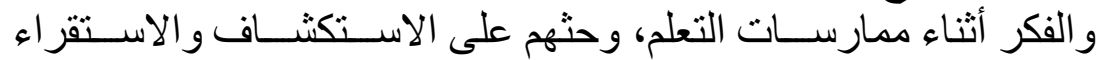

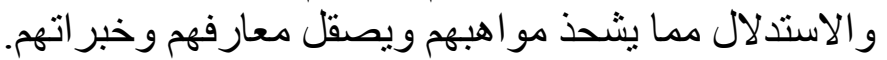

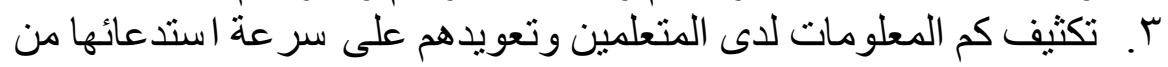

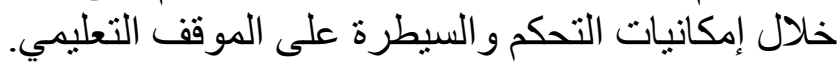
ع. تعزيز دافعية التعلم لدى الأفر اد بتمكينهم من رؤية التهائ نتائج ما يتعلمون.

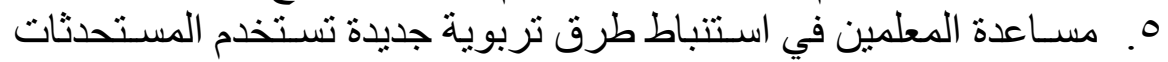

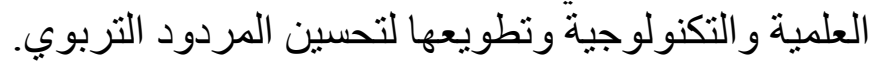

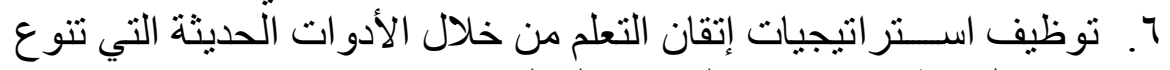
في شكل وطرق اكتساب الخبرة و المعلومات.

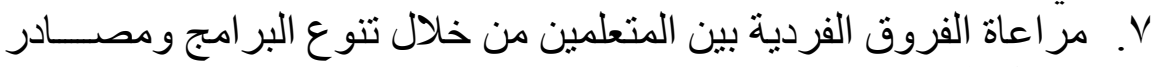
وشكل الخبر ات المقدمة. ^. اختفاء مظاهر الخوف والقلق من استخدام التكنولوجيا الحديثة أثناء عملية التعلم. • 1 ـ تقديم تغذية راجعة فورية وبجميع أشكالها التعزيزية و التصحيحية.

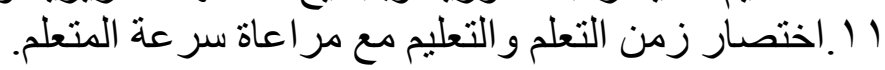

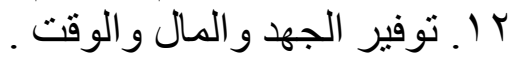
لا بد أن نعي أن تكنولوجيا المعلومات واتوات والاتصالات يمكن أن تكون أدوات تدريسية

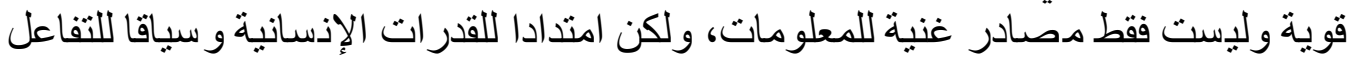

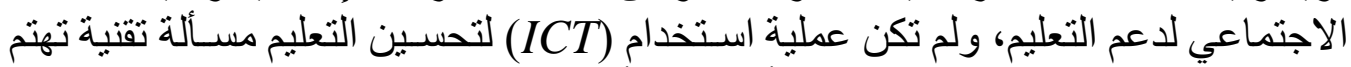

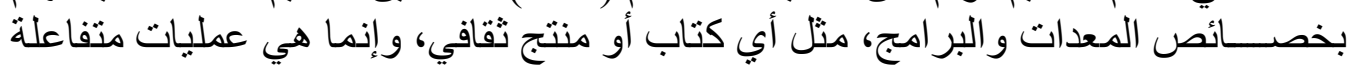


تعمل في بيئة اجتماعية متداخلة تتفا عل مع الر فاق و المعلمين و الأســـرة و المدرســــة .(Mooij, 2004)

من الاهتمامات الرئيســية في قطاع المدارس في جميع أذحاء العالم في العقود

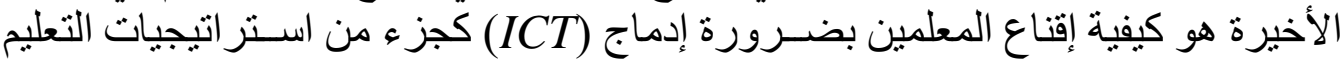

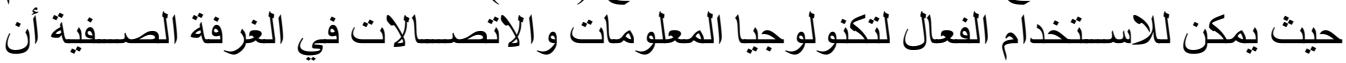

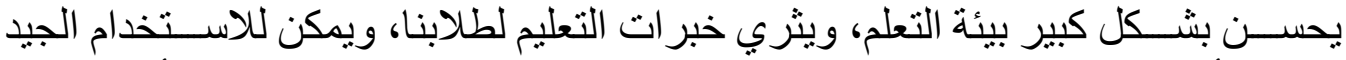
(ICT)

المستمر والتطور الثخصي (Galanouli, Murphy, \& Gardner, 2004).

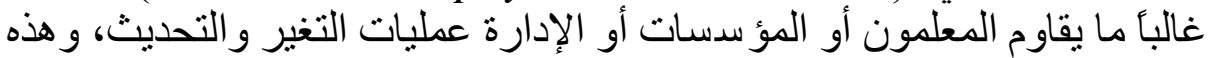

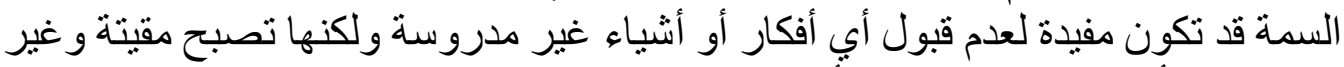

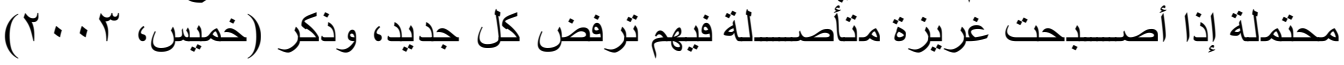

مجمو عة من الأسباب التي تؤدي إلى رفض عملية التغير و التطوير ، منها:

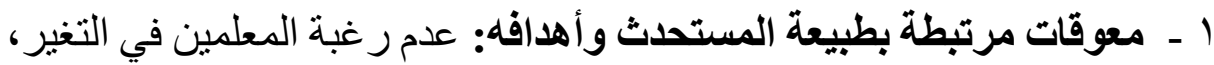

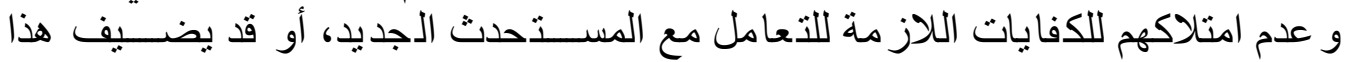
المستحدث أعباءً يشعر أنها متعبة، إضافة إلى عدم مر افقة هذا المستحدث الحوافي افز المادية

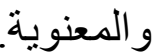
r - معوقات خاصــــة بالإدارة التعليمية: قد تكون الإدارة من النمط البيروقر اطي الإني

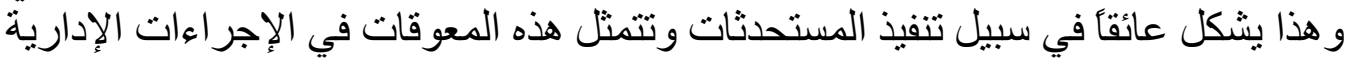

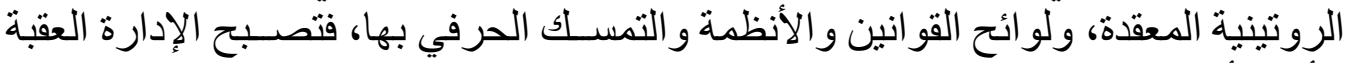

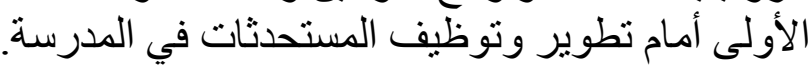

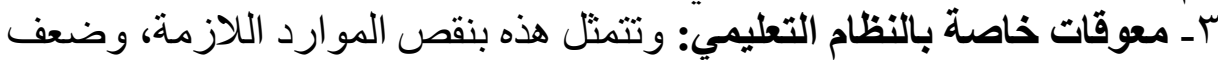

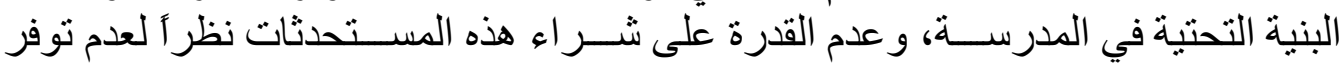
الموارد المالية الكافية.

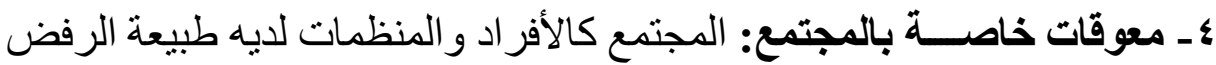

لكل ما هو جديد و غريب على المجتمع، خاصة ماه ما يتعلق بالعملية التربوية.

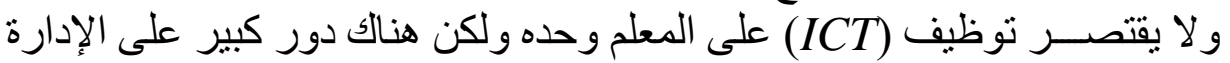

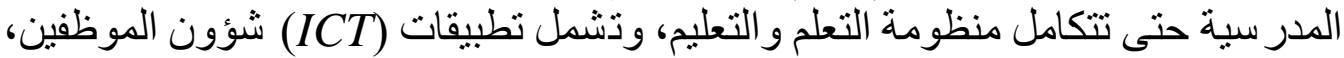

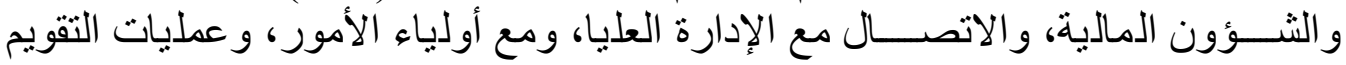

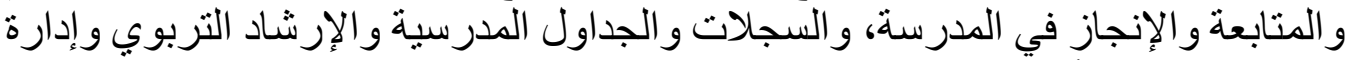

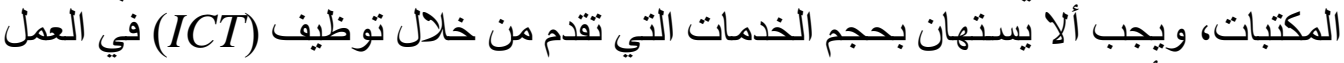

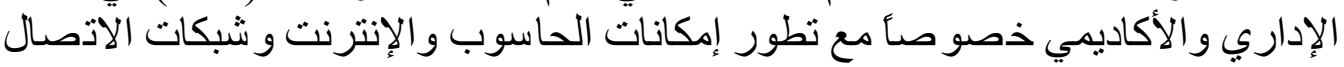

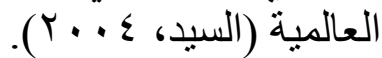

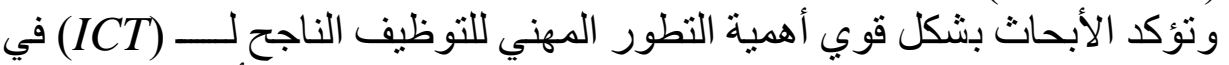
الغرفة الصفية، فقد وجد بايلر وريتشي (Baylor \& Ritchie, 2002) أن الدعم للتطور 


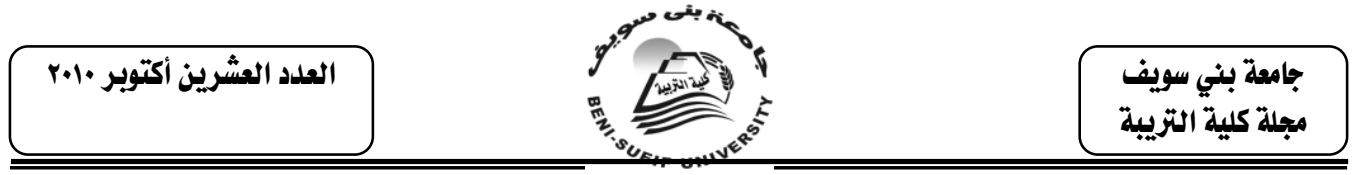

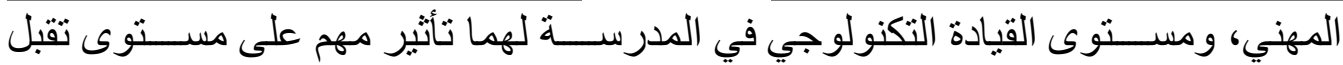

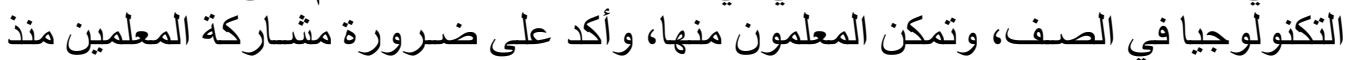

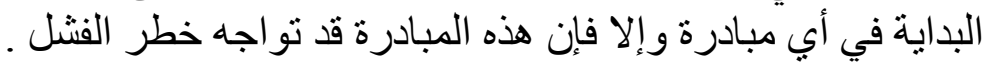

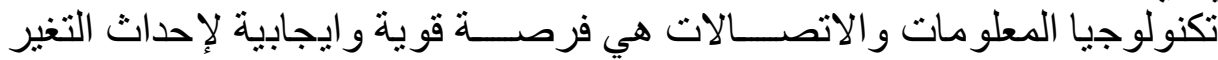

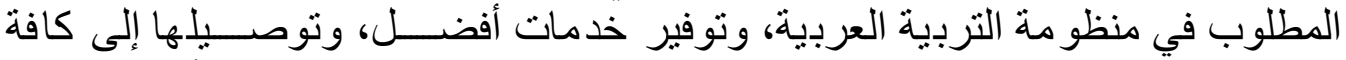

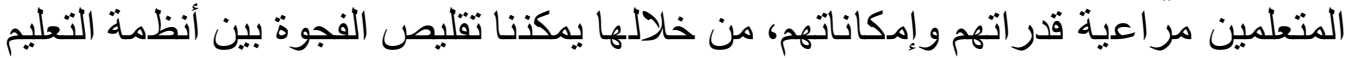

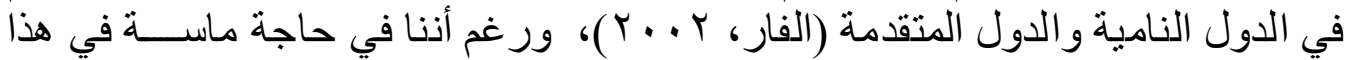

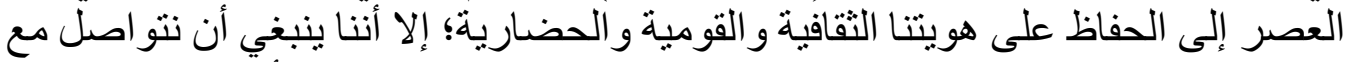

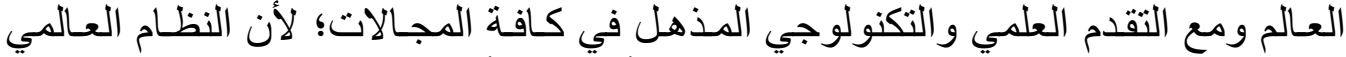

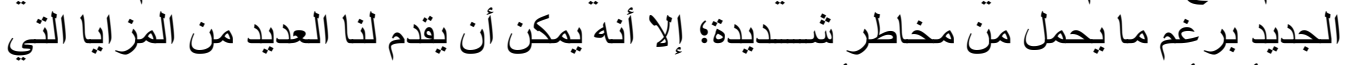
من شأنها أن تتهض بمجتمعنا إذا أحسنا التعامل معها بذكاء وحذق وفئ وفطنة.

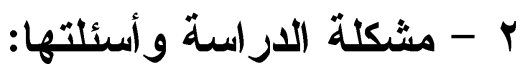

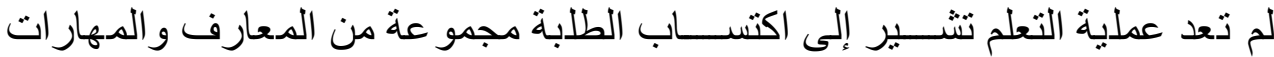

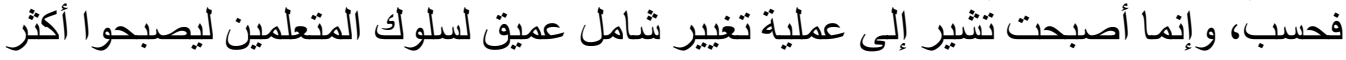

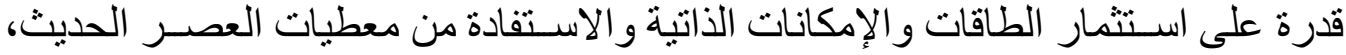

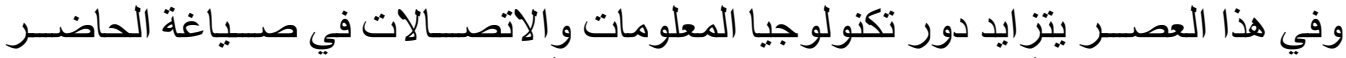

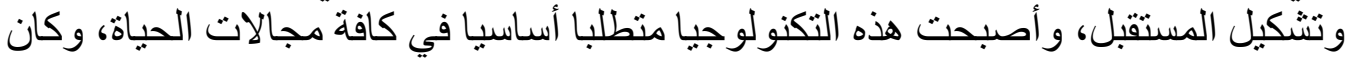

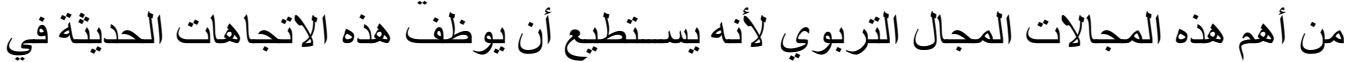

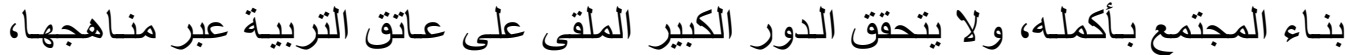

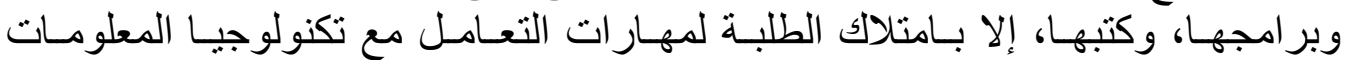

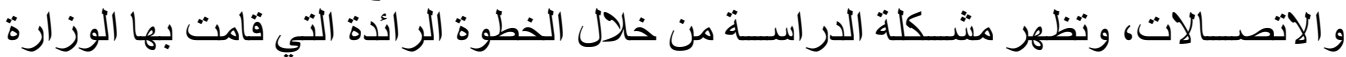

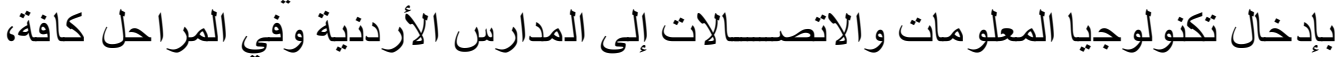

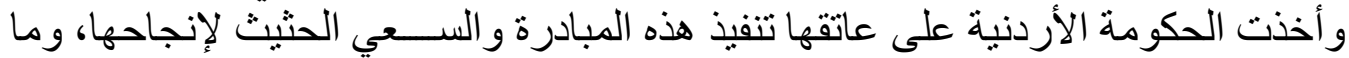

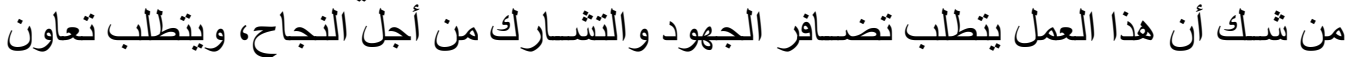

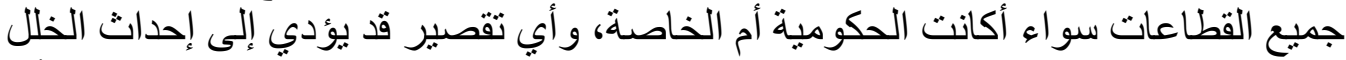

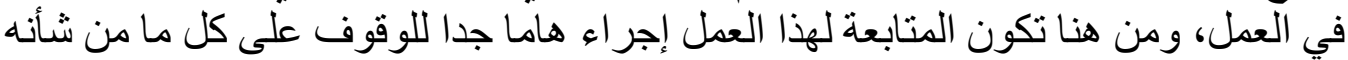

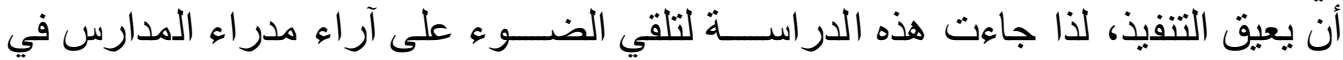

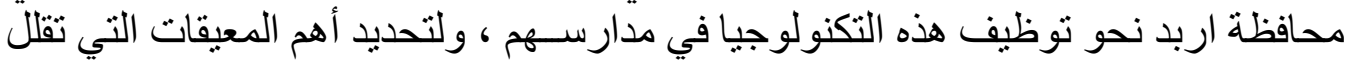

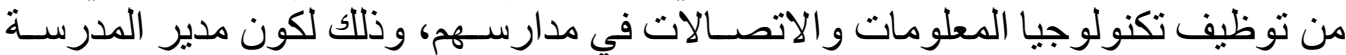

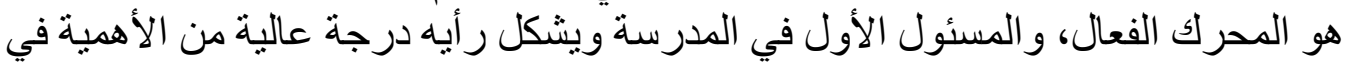

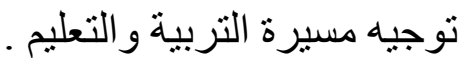

\section{وبشكل أكثر تحديدا جاءت الارليمة استة لتجيب عن الأسئلة التالية:}

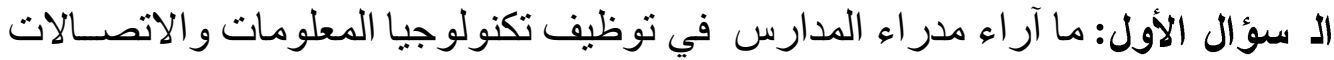
في عمليات التعلم و التعليم الصفي ؟ آراه الصدار 


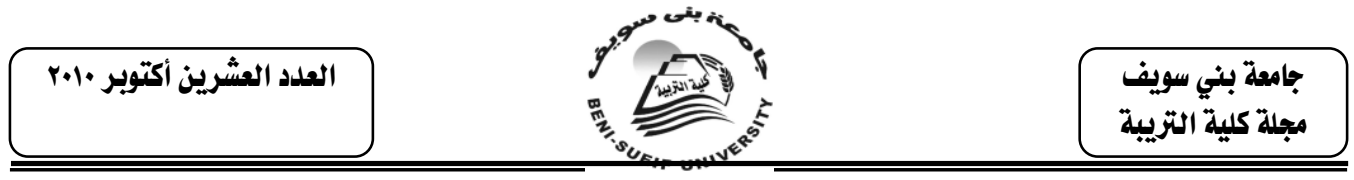

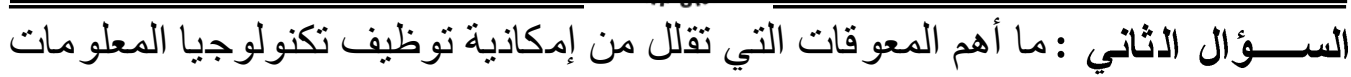

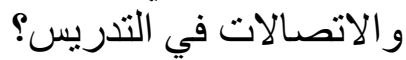

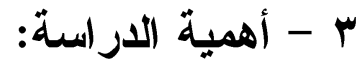

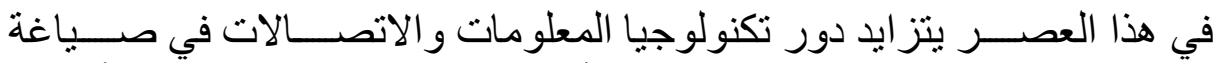

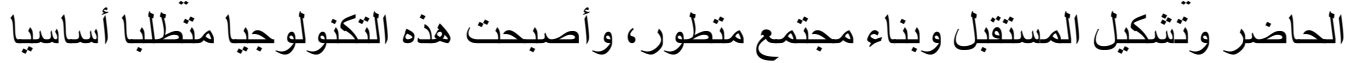

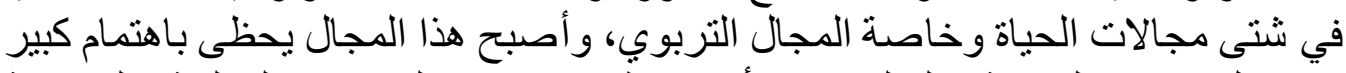

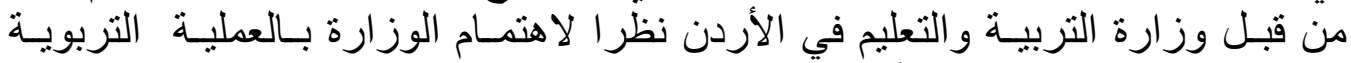

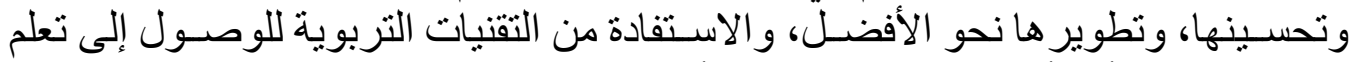

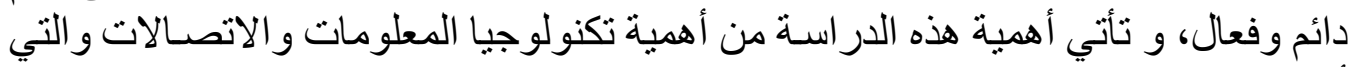

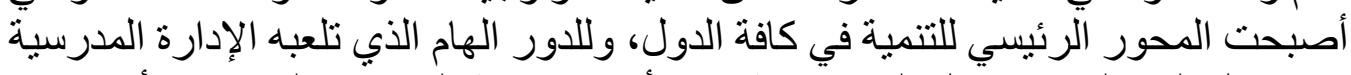

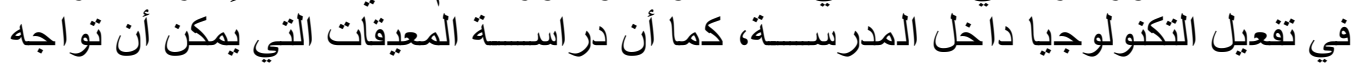

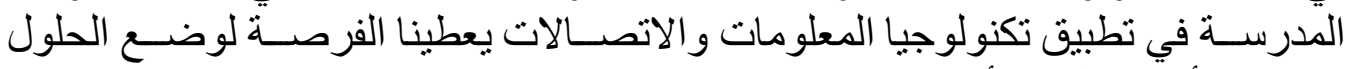

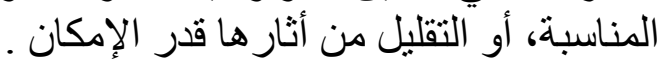

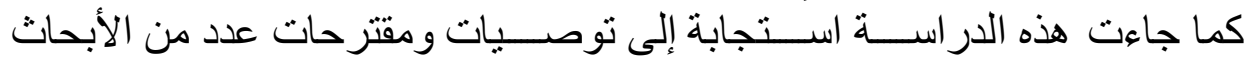

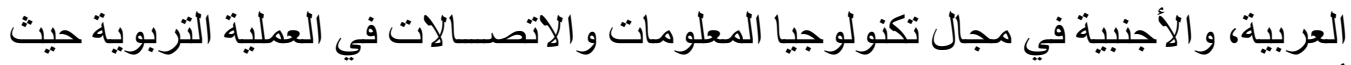

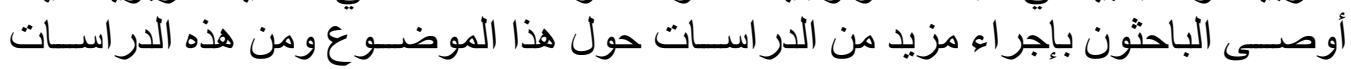

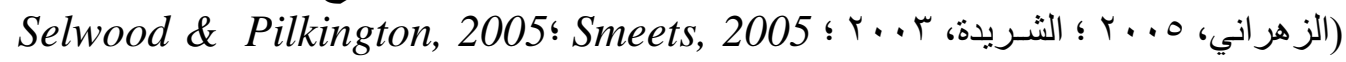
(Alsodi \& Adaileh, 2004 ؛ Lakkala \& Legtinen, 2004 ؛ ع - التعريفات الإجر ائية: نظر الورود بعض المصنطات الاجرات و والمفاهيم في الدراسة و التي قد تحمل معاني مختلفة سيتم تعريفها بحسب المعنى منها في هذه الدر استة، وهي المي:

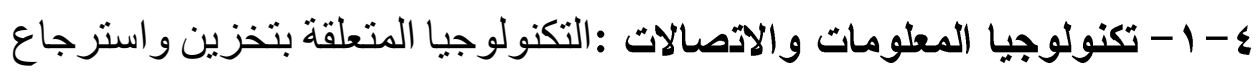

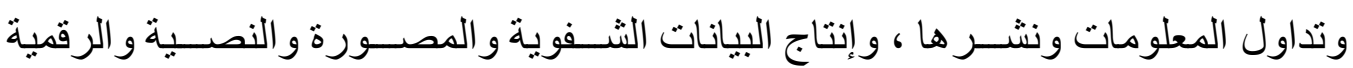

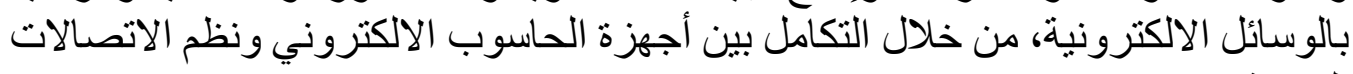

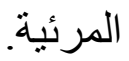

ع - ب - المناهج المحوســـبة: تللك المناهج التي قامت وزارة التربية والتعليم

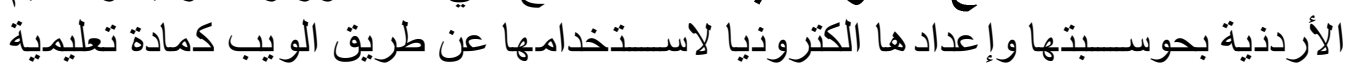

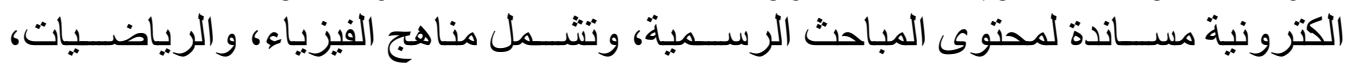

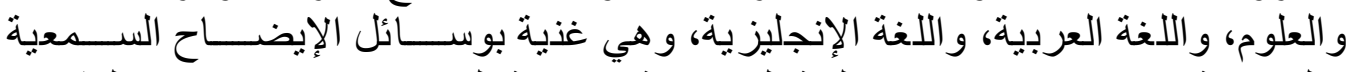

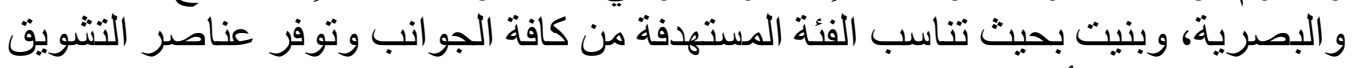
و الإثارة و التفاعل أثناء عمليات التعلم. 
ع - r - معوقات استخدام تكنولوجيا المعلومات والاتصالات: تشمل كافة الأمور التي

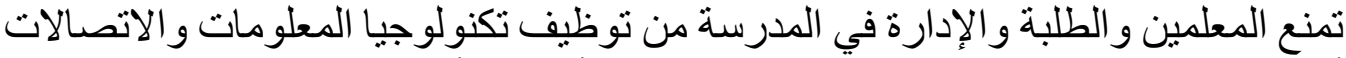
أو تقلل من استخدامها، وقد تكون المعوقات المدات بشرية أو تقنية أو مادية.

\section{0 - مدود البحث}

تتحدد حدود هذا البحث بالمدارس الحكومية في محافظة اربد و التابعة لمديريتي

$$
\text { تربية اربد الأولى واربد الثانية. }
$$

7 - الار اسات السابقة

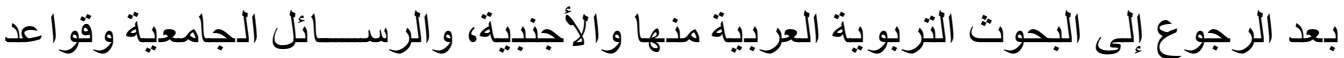

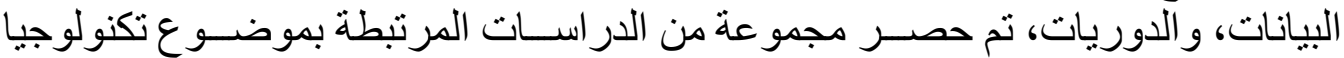

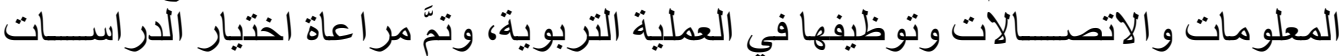

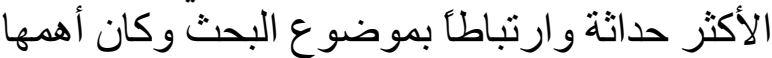

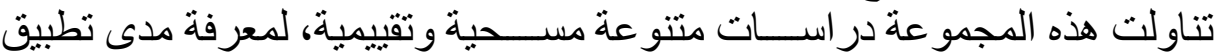

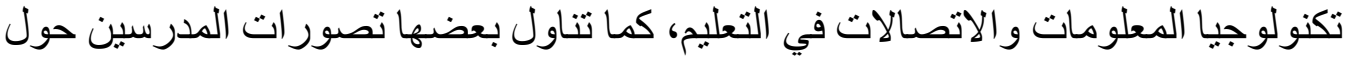
و المعو قات التي تو اجههم وتحد من تفعيلها في الجانب التربوي، و اتجا هاتهم نحو

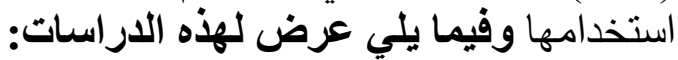

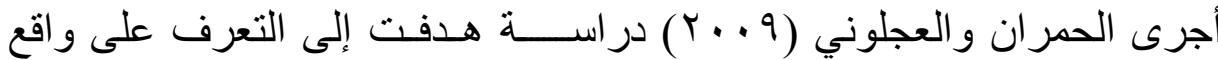

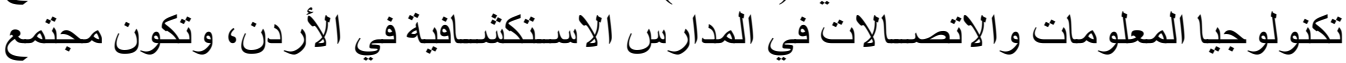

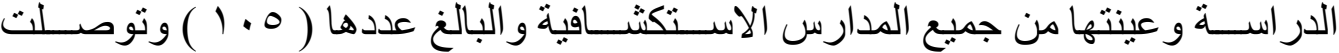

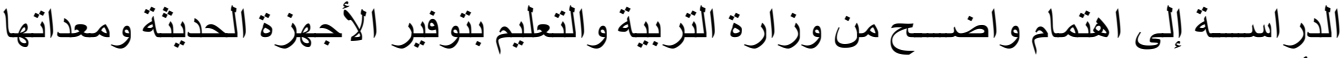

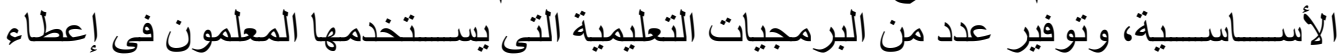

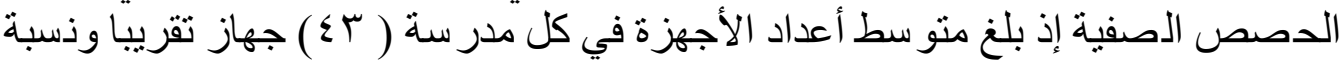

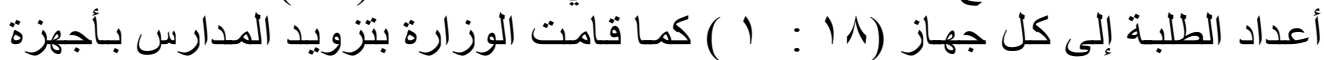

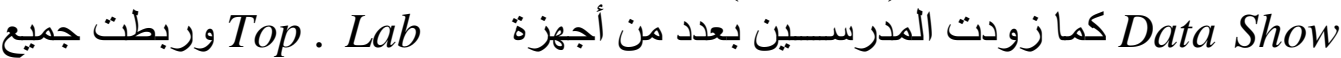

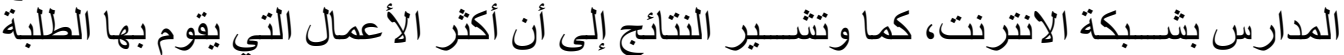

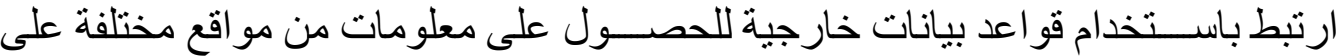

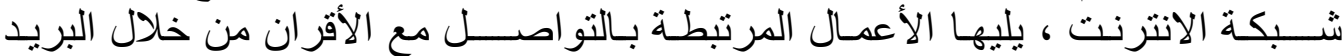

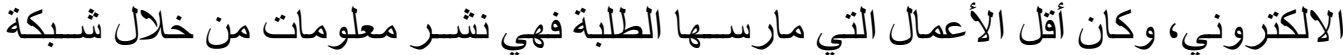

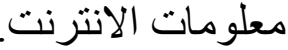

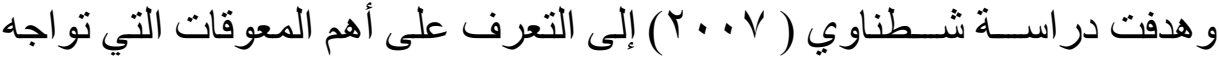

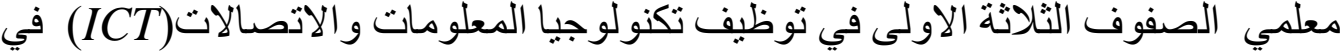

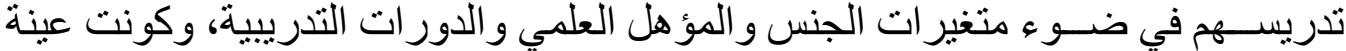

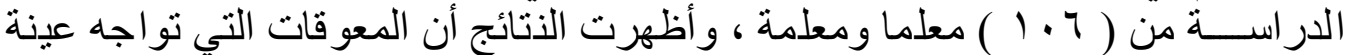
الدر اســة في توظيف (ICT) في العملية التعليمية كانت كبيرة في مجال بناء قدر الت ات المعلم 


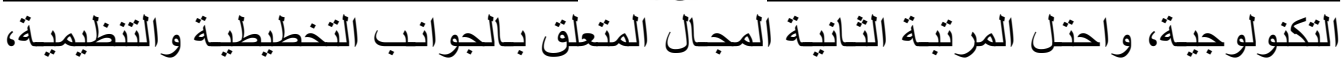

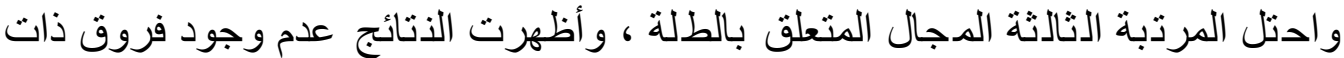

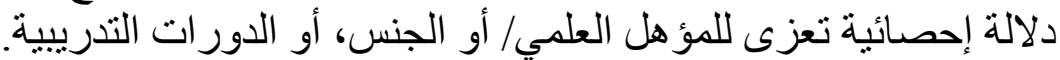

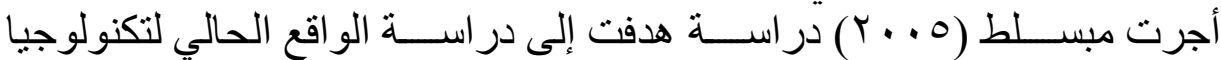

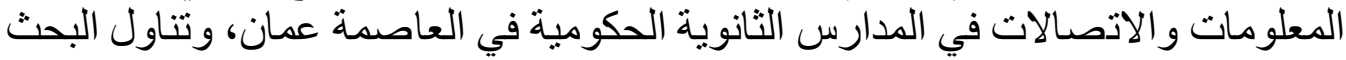

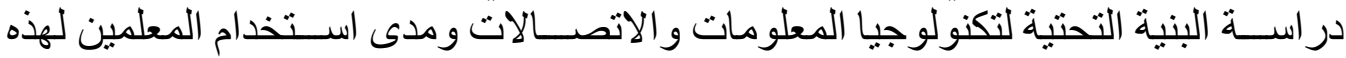

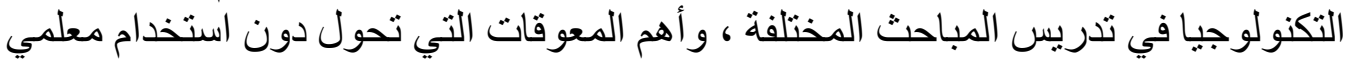

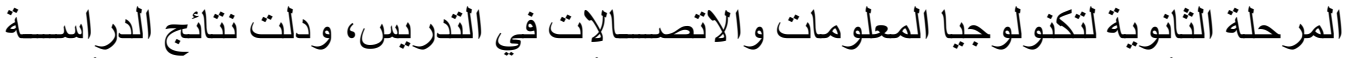

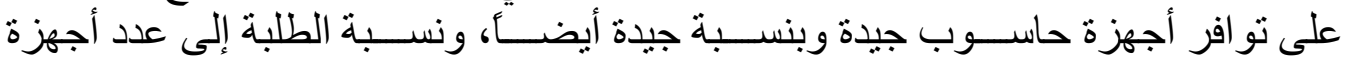

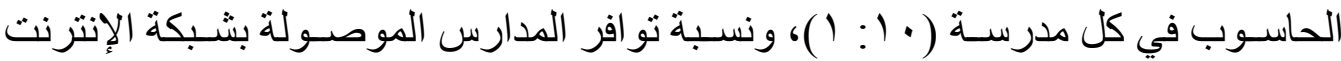

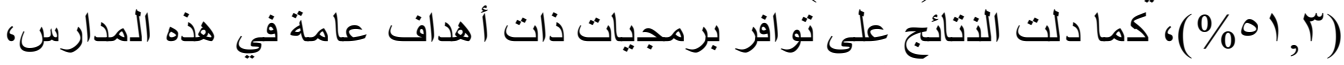

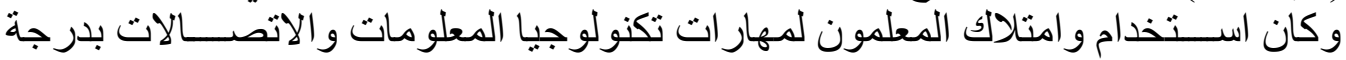

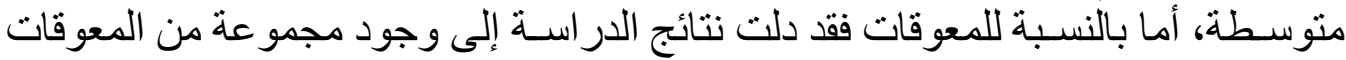

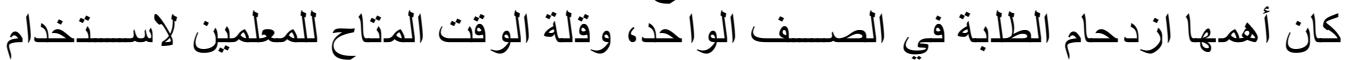

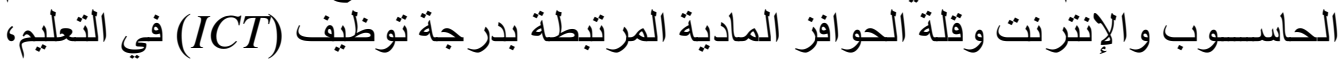

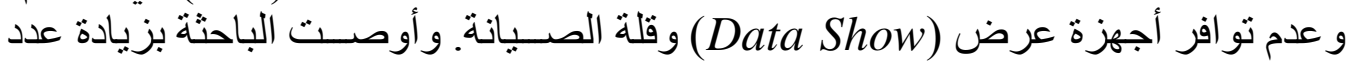
أجهزة ومختبر ات الحاسوب في جميع مدارس المملكة، وربط جميع مدارس المملكة بشبكة

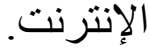

و هدفت در اسة الز هر اني ( 0 . . ب) إلى تقييم و اقع استخدام أعضاء هيئة التدريس

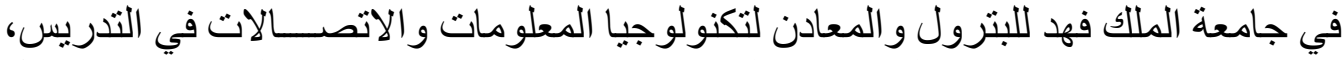

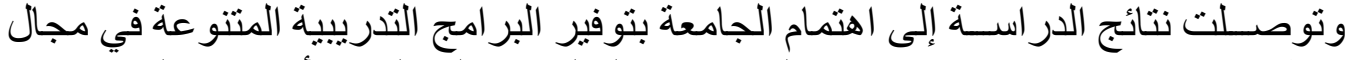

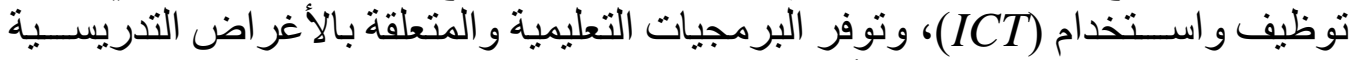

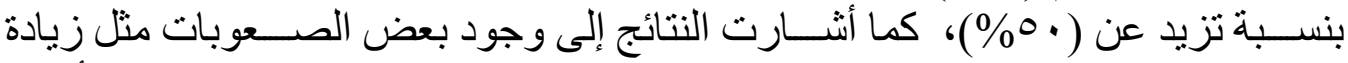

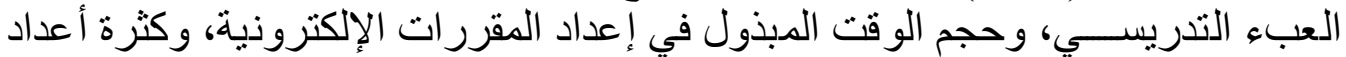

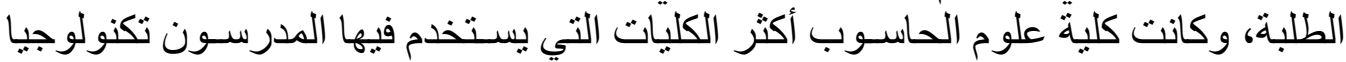

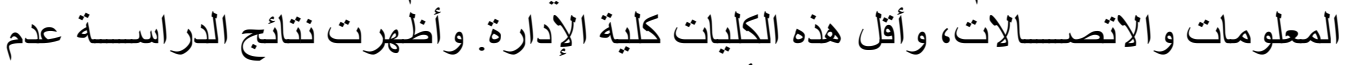

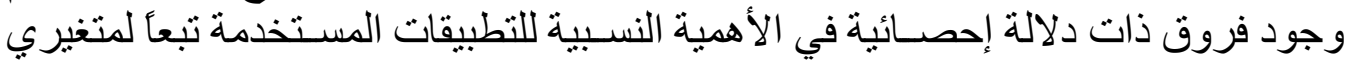

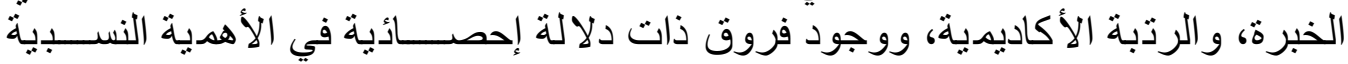

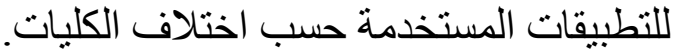
وفي ايرلندة أجرى الباحث سمينس (Smeets, 2005 ) در اسة بعنو النيان هل تساهم

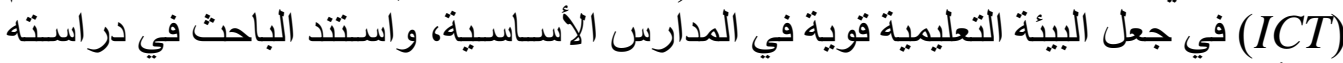

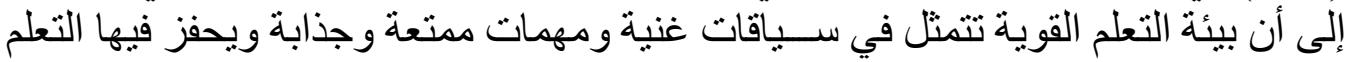

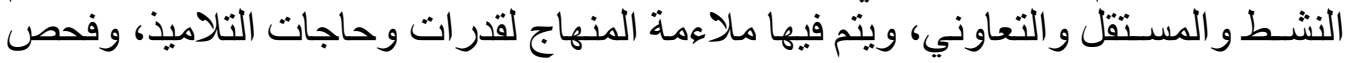

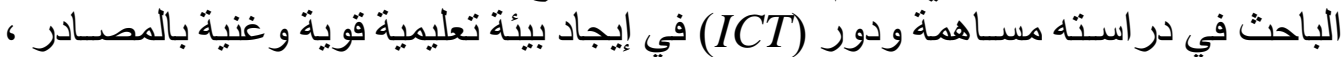

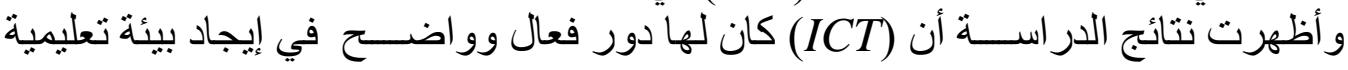


تعلمية قوية، حيث أن كثير ا من المعلمين يستخدمون عدة عناصـر من بيئة التعلم القوي في صفوفهم وخاصة تقديم مهمات جذابة ومشوقة ور إية التهات التعلم النشط و المستقل، ولكن تبين

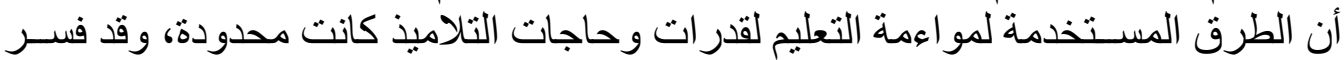

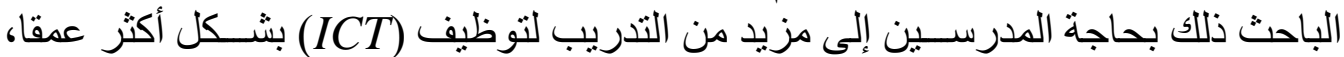

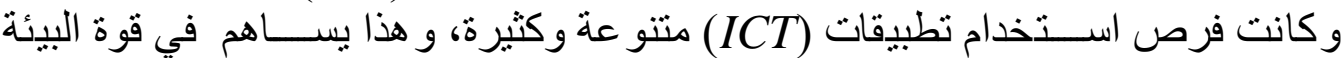

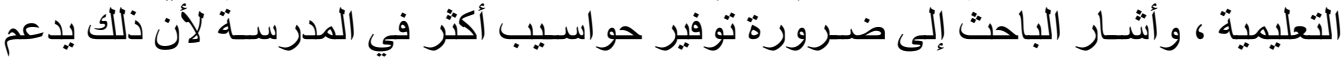

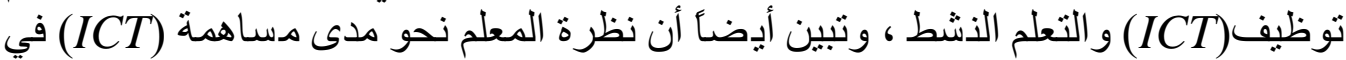

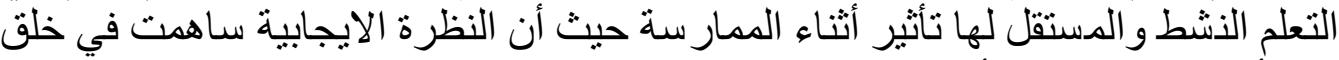

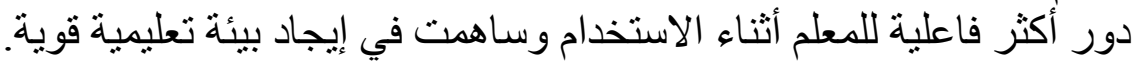

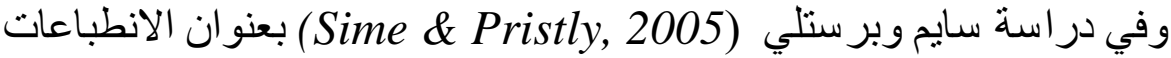

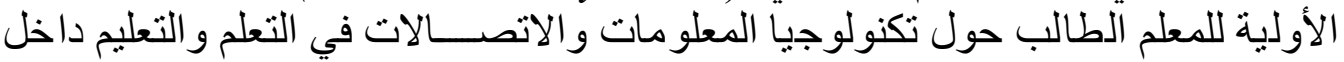

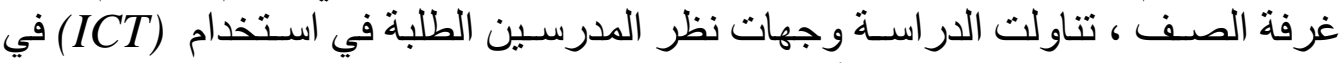

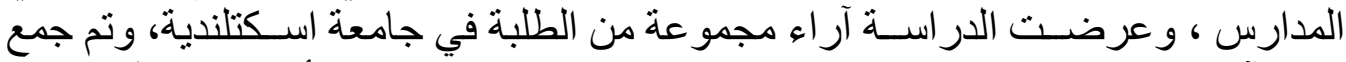

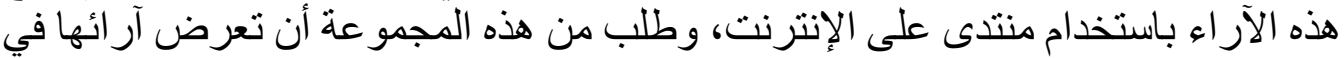

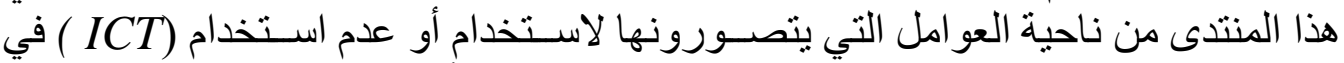

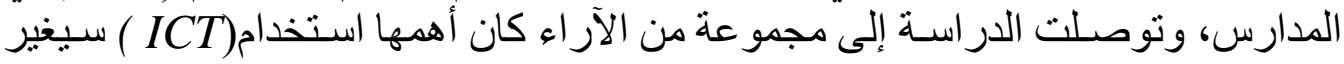

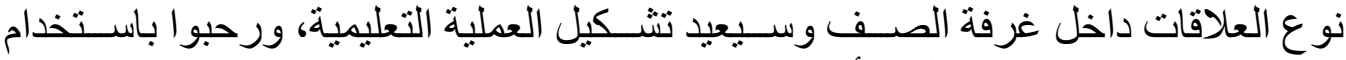
(ICT)

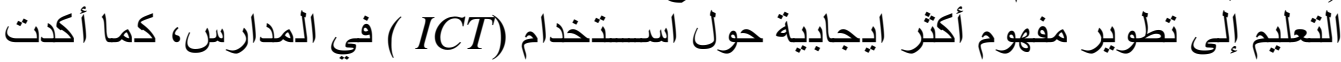

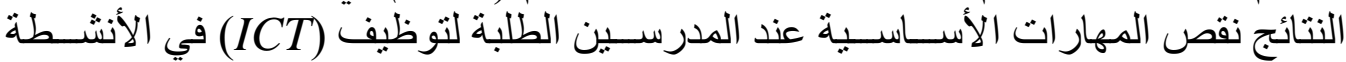

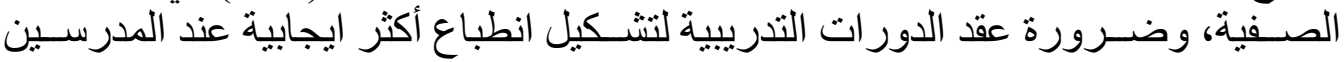
الطلبة فبل تخرجهم من الجامعة لتوظيف (ICT) في الغرفة الصــفية عند تعبينهم في مهنة التعليم بعد تخرجهم.

وتحت عنوان "تكنولوجيا المعلو مات و الاتصــــالات في المدارس الثانو ية: دور

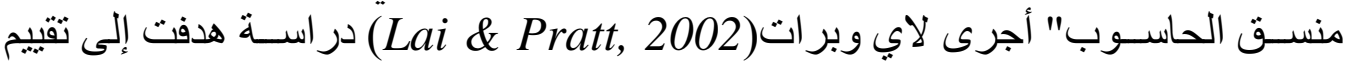

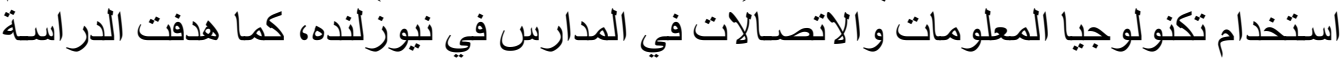

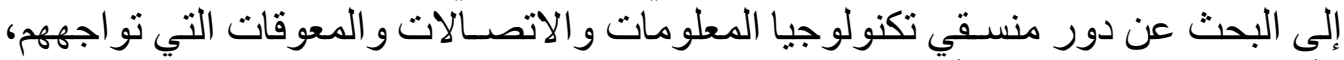

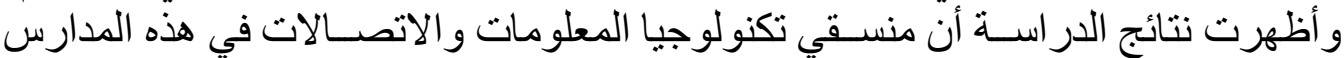

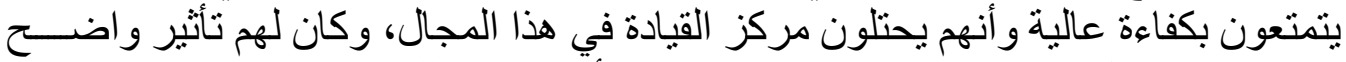

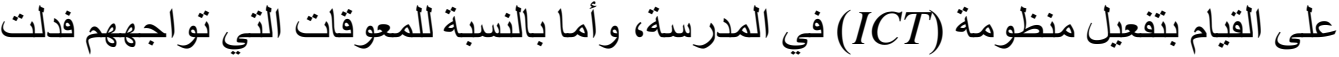

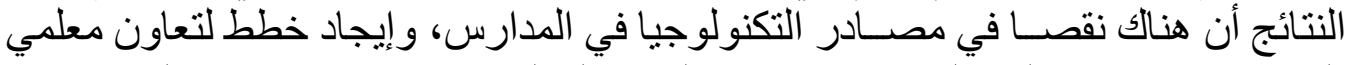

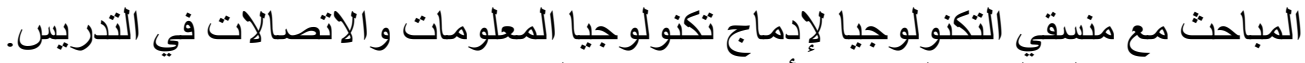

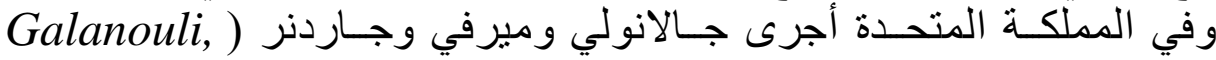
(Murphy \& Gardner, 2004 (ICT) 
للبرنامج التدريبي (NOF Opportunities Fund (NOF لكل معلمي المملكة المتحدة،

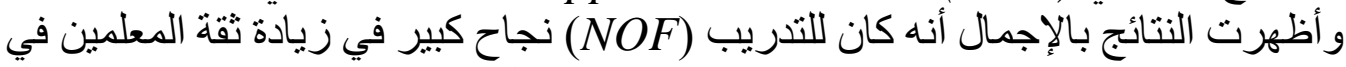

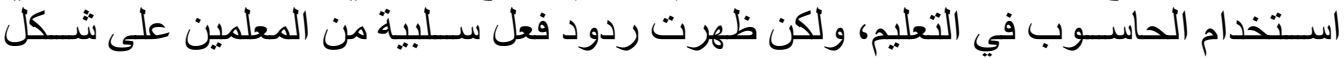

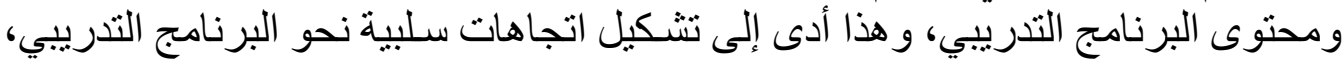

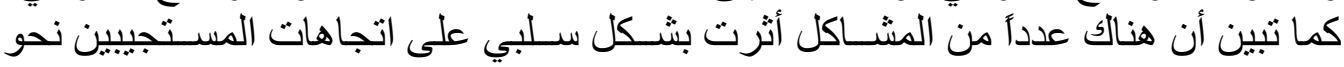

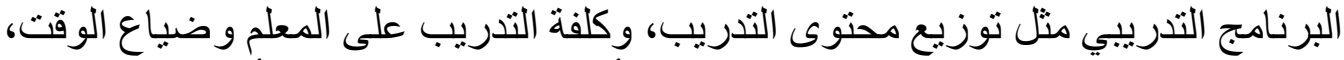

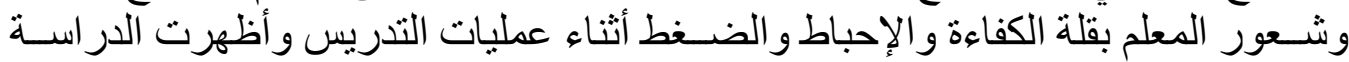
نتائج ايجابية حول آر اء المعلمين في استخدام وتوظيف (ICT) في المدروسة.

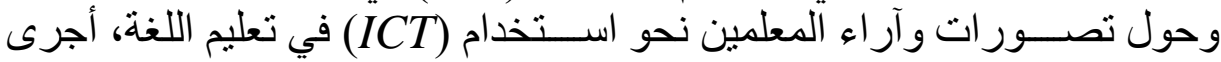

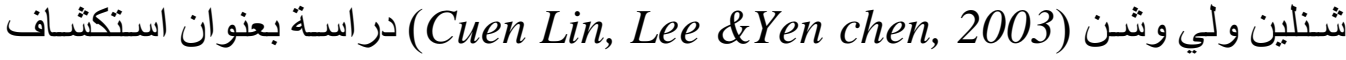

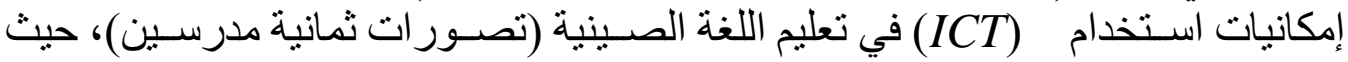

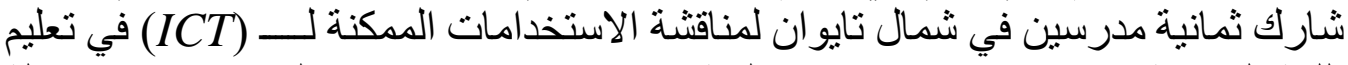

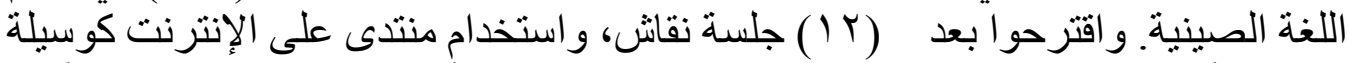

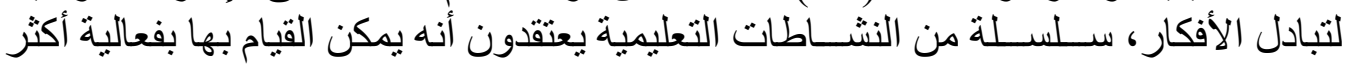

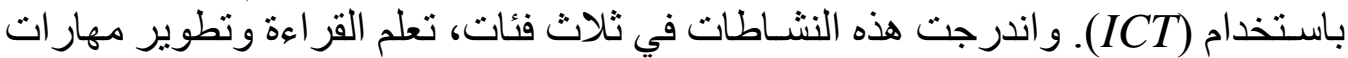

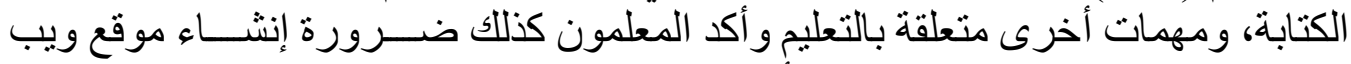

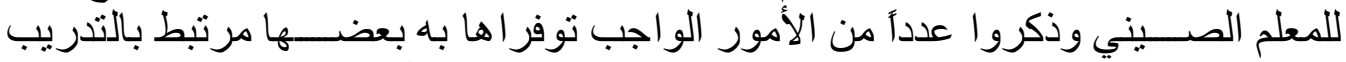

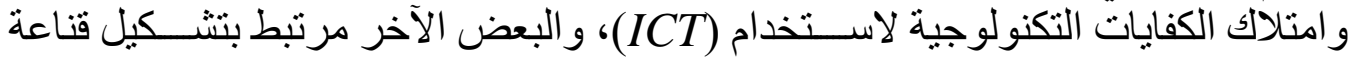

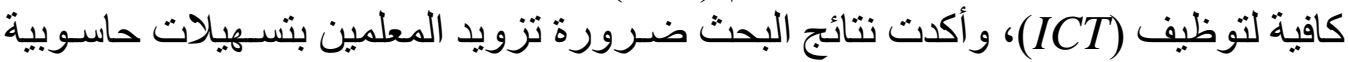

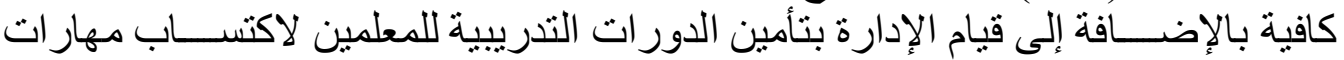

التعامل مع (ICT) وتوظيفها في تعليم اللغة الصينية.

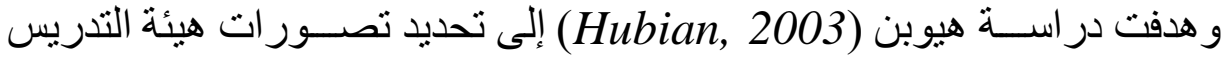

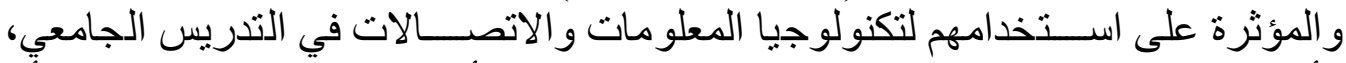

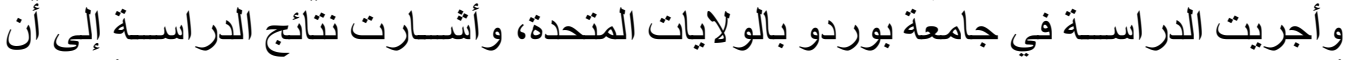

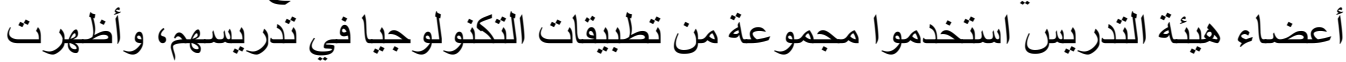

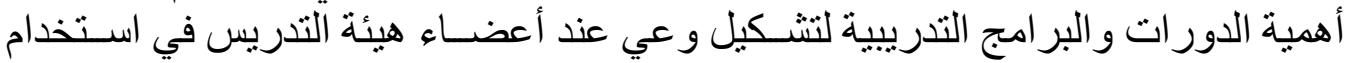
(ICT)

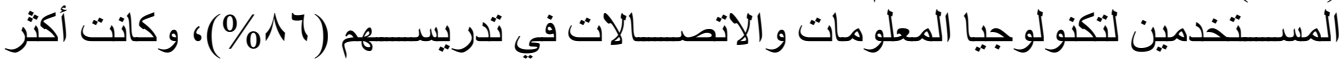

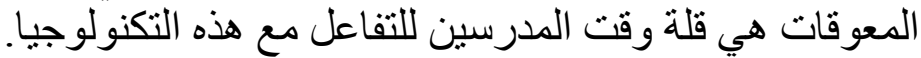

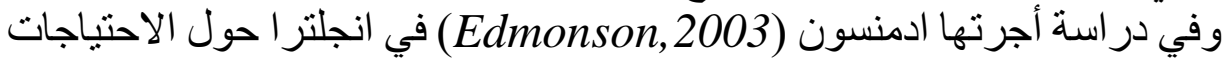

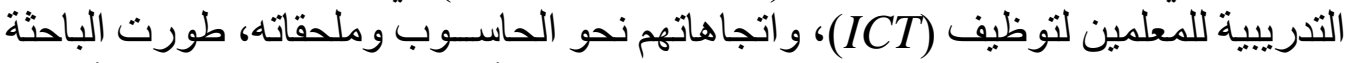

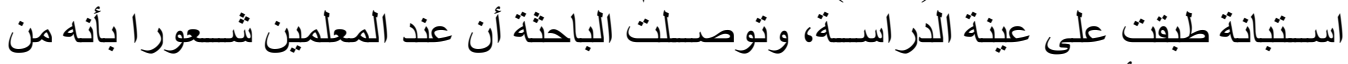

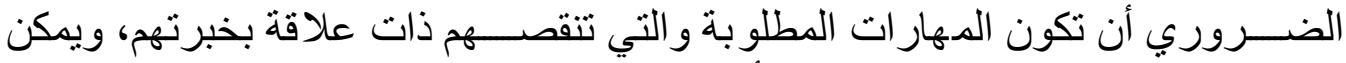

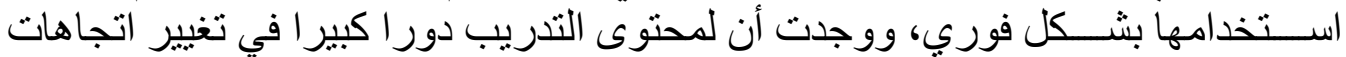

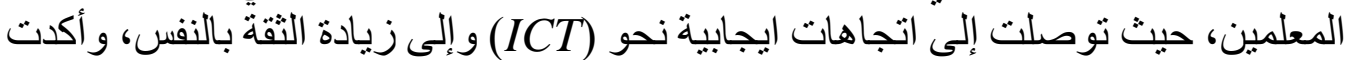




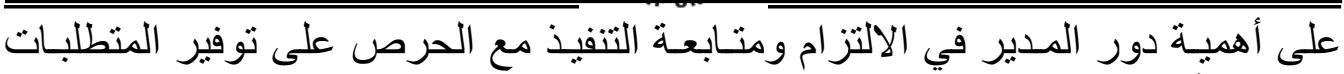

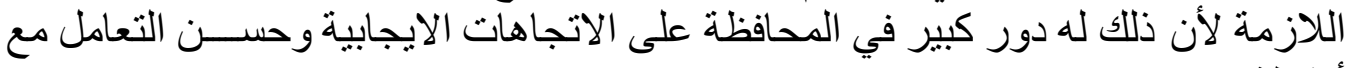
أنشطة (ICT).

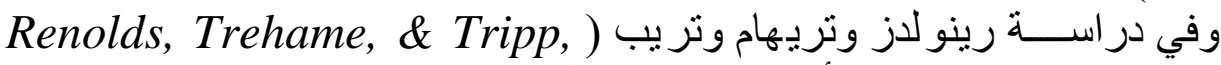

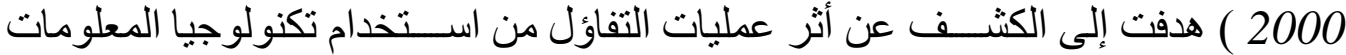

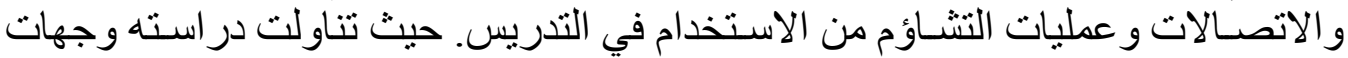

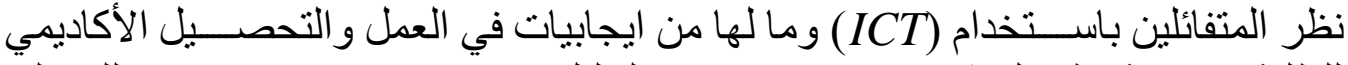

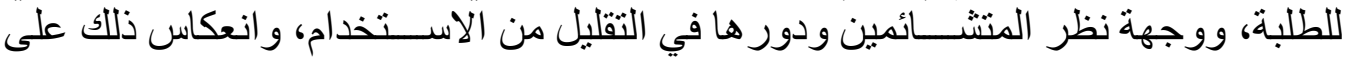

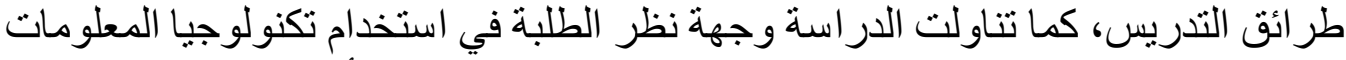

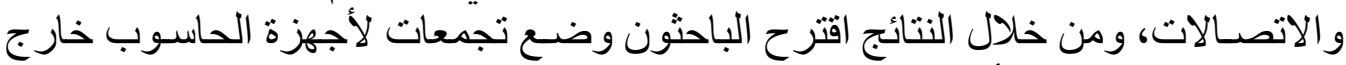

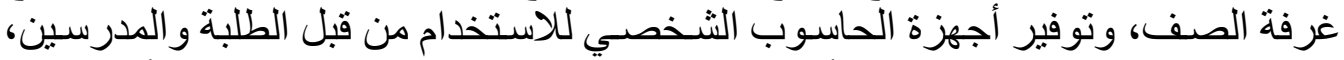

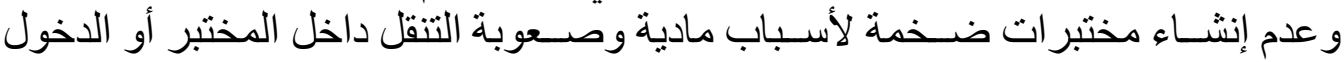

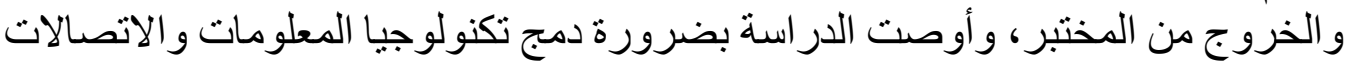
في المناهج المدرسية.

\section{من خلال الإطلاع على الاراسات السابقة نلاحظ ما يلي:}

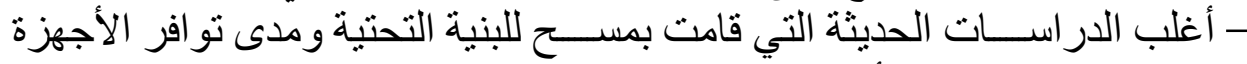

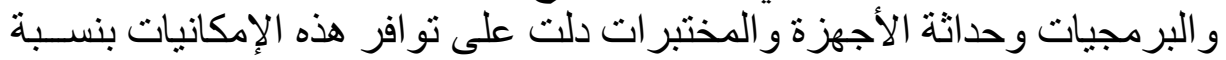

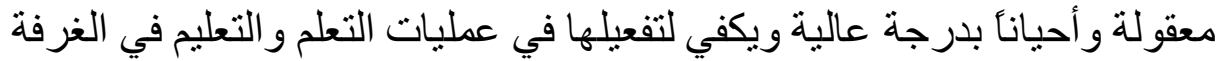

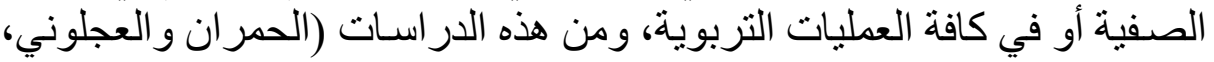

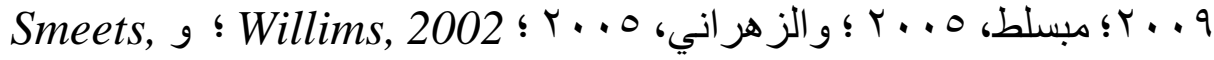

. 2005

- تناولت بعض الدراســـات الاتجاهات و التصــــور ات نحو اســـتخدام تكنولوجيا

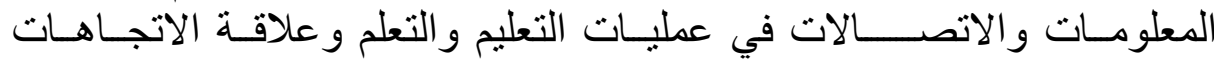

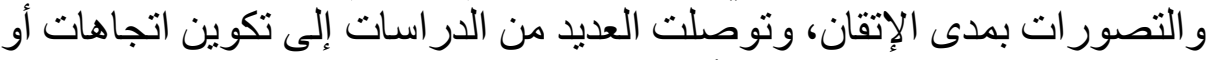

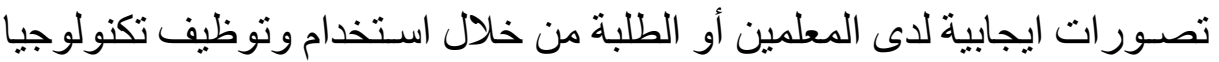

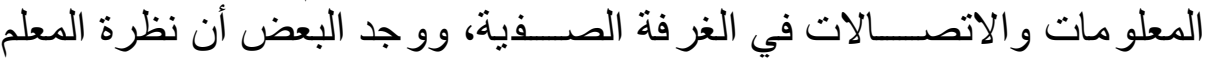

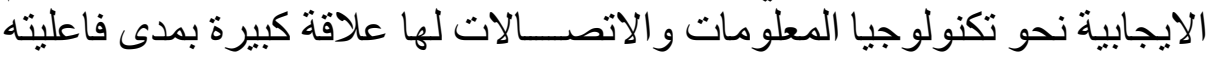

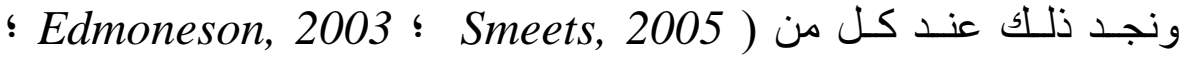
. (Reunolds, 2002 ؛ Hubian, 2003

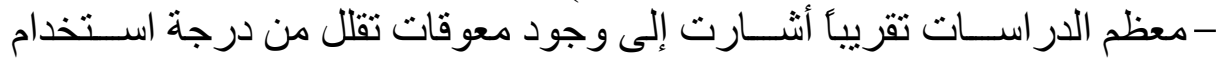

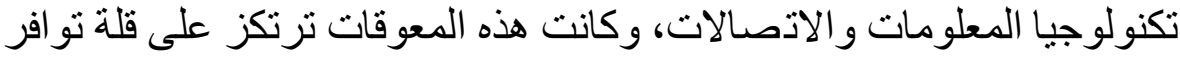

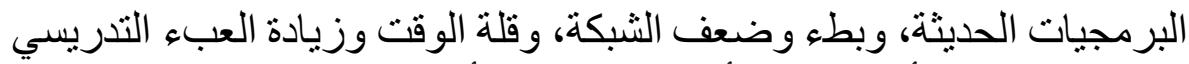

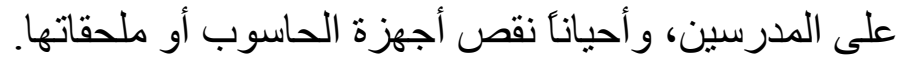

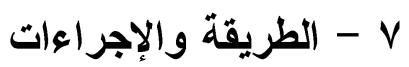

V - V 


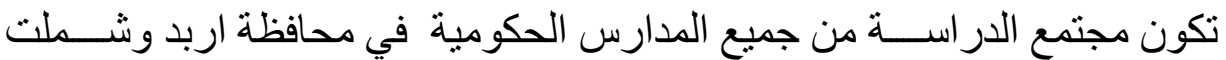

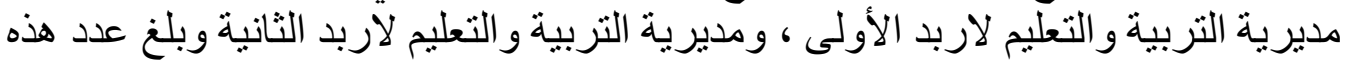

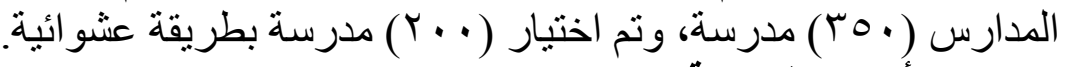

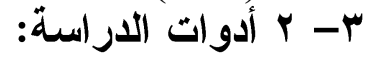

قام الباحث بتطوير استبيان تكون من جز أين وهما:

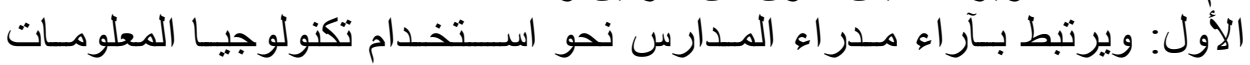

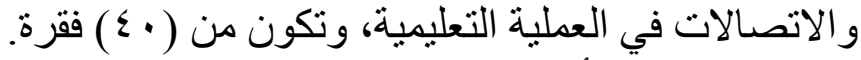

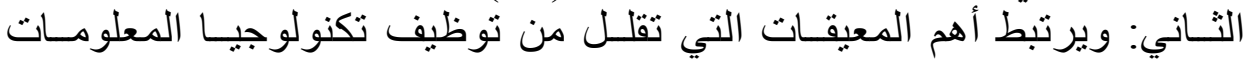

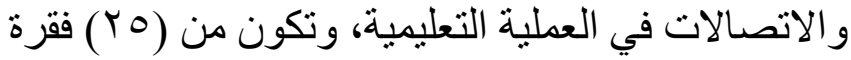

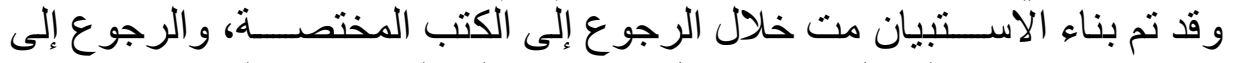

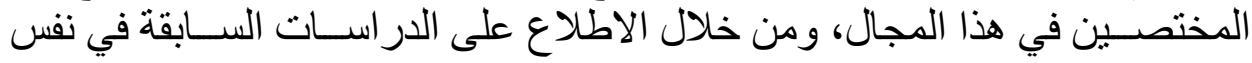

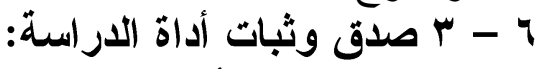

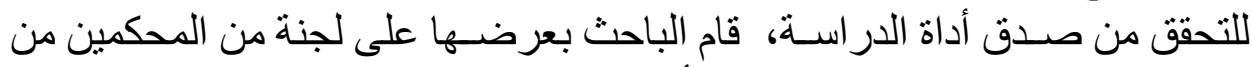

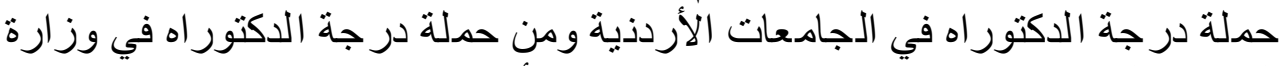

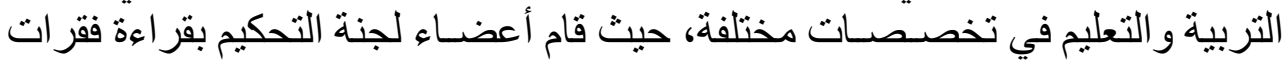

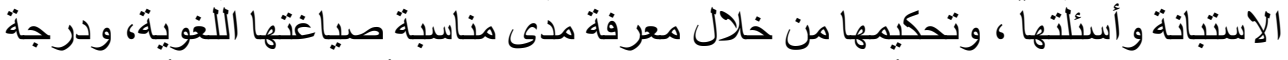

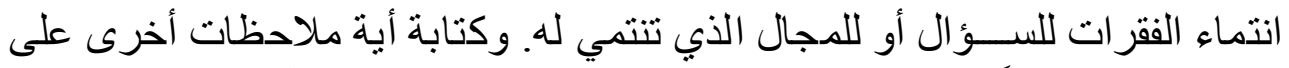

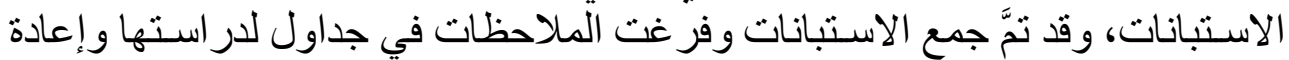

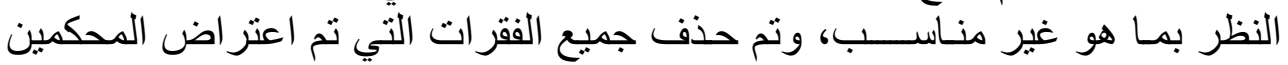

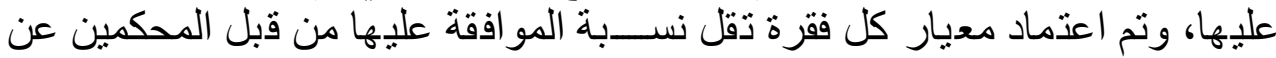

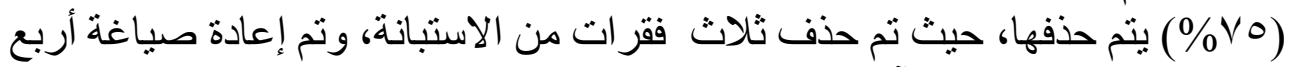

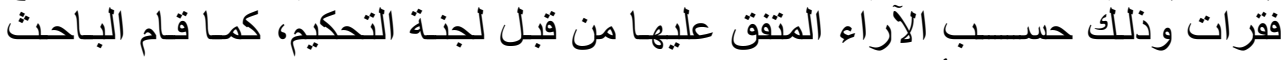

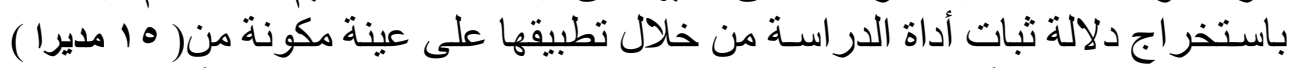

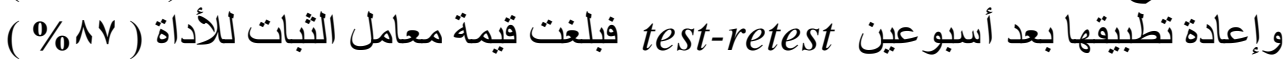
وتعتبر القيمة مقبولة لأغر اض اضلف البحث العلمي.

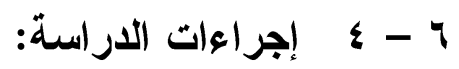
اتبعت هذه الار اسة الإجراء الاعات التالية:

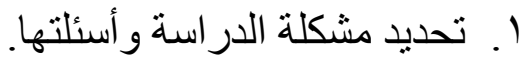

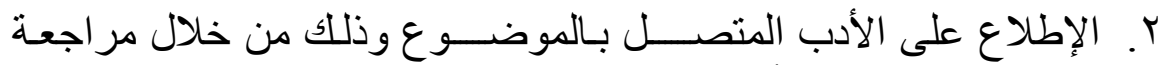

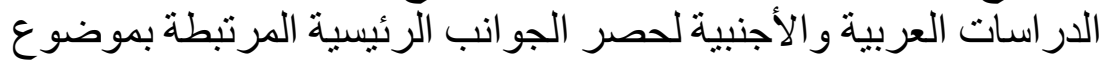
الار اسة.

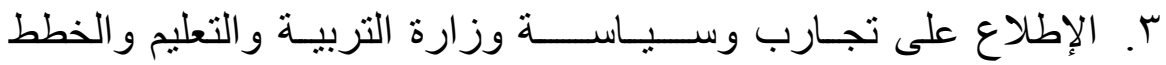

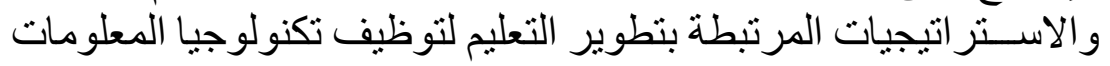




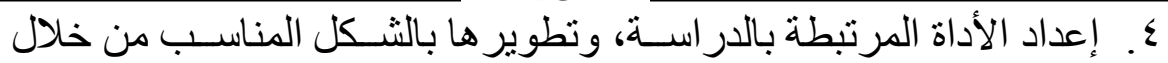

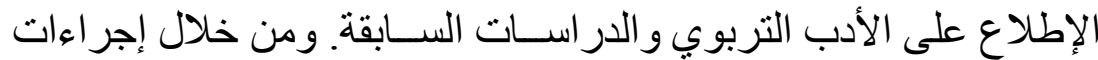

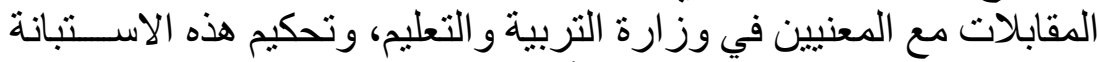

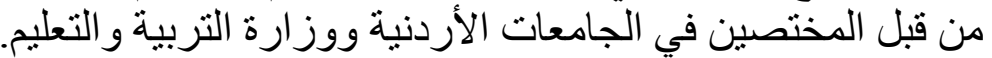

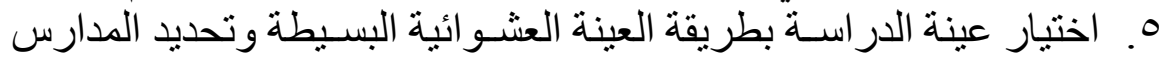
المعية بالإجابة عن فقر ات الاستبانة.

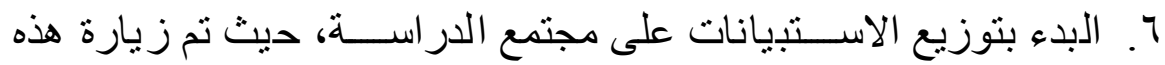

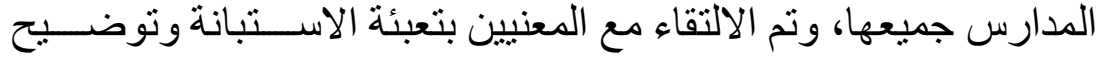

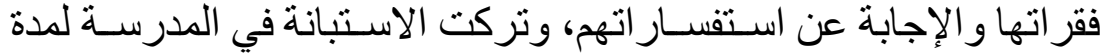

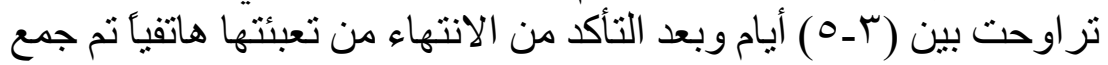
هذه الاستبيانات.

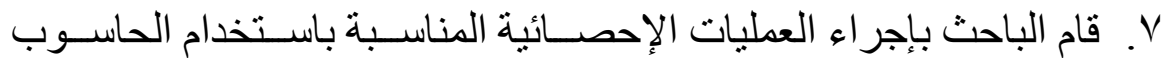

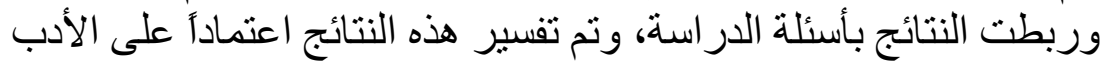

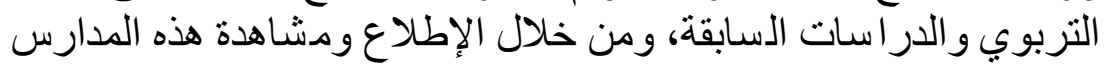
على أرض الو اقع.

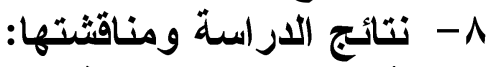

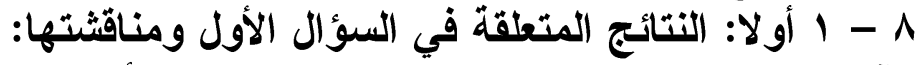

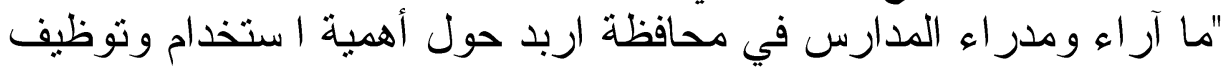

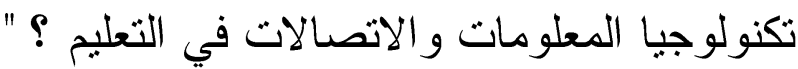

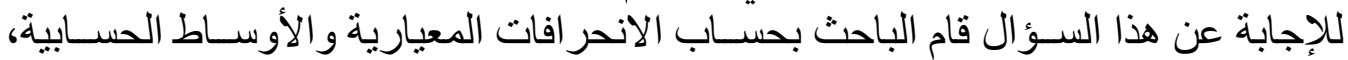

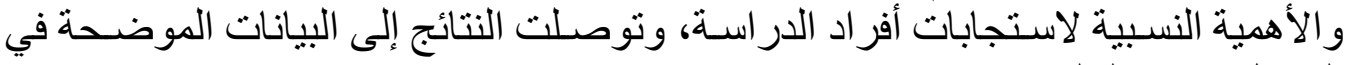

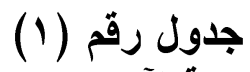

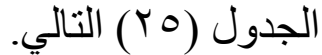

المتوسطات الحسابية والأهمية النسبية لآراء مدراء المدارس نحو توظيف تكنولوجيا

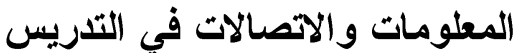

\begin{tabular}{|c|c|c|c|c|}
\hline الأهمية & الوسط الحسابي & الإخر اض & الفقرة & الرقم \\
\hline$\% \wedge 0$ & \&.Yo & $\cdot . \wedge \wedge$ & توفر (ICT) مصادر متنوعة للحصول على الحبرة. & 1 \\
\hline$\% \wedge \varepsilon$ & $\varepsilon . r$. & $\cdot . \mathrm{VV}$ & التعلم باستخدام (ICT) مشوق ومتع للطلبة. & $r$ \\
\hline$\% \wedge \mu$ & $\{.10$ & $1.1 \varepsilon$ & تسهل (ICT) اكتساب الحخبرة والمعلومات. & $r$ \\
\hline$\% \wedge \uparrow . \varepsilon$ & s.1r & $1 .+r$ & تسهل (ICT) تنويع أساليب التعلم والتعليم. & $\varepsilon$ \\
\hline$\% \wedge r$ & «.1. & $.9 \leqslant$ & دور المعلم. & $\bullet$ \\
\hline$\% \wedge 0 . \varepsilon$ & $\varepsilon . \wedge$ & 1.10 & البحث العلمي. ستخدام (ICT) على الطالب والمعلم اكت ساب مهارات & 9 \\
\hline
\end{tabular}




\begin{tabular}{|c|c|c|c|c|}
\hline$\% \wedge \bullet . \varepsilon$ & $\varepsilon . \wedge$ & $r .0$ & ينمي (ICT) مهارات التفكير عند الطلبة. & $\checkmark$ \\
\hline$\% \wedge \bullet . 乏$ & $\varepsilon . \wedge$ & 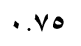 & يقلل استخدام أدوات (ICT) من الروتين اليومي للمعلم. & $\wedge$ \\
\hline$\% \wedge \bullet . \varepsilon$ & $\varepsilon .+V$ &..$\wedge \wedge$ & تستــاهم (ICT) في إكســــاب التلاميذ القدرة على التو جه المهني & 9 \\
\hline$\% \wedge 1 . \varepsilon$ & $\varepsilon . .0$ & 1.00 & وإيصالما. & $1 \cdot$ \\
\hline$\% \wedge 1 . \varepsilon$ & $\varepsilon .0$ &..$\wedge \Lambda$ & تعطي (ICT) تنوعاً أكبر في أنماط التفكير عند المعلم والمتعلم. & 11 \\
\hline$\% \wedge \cdot .7$ & $\varepsilon .+\mu$ & 1.07 & تســـاهم (ICT) في ربط المعلم والمتعلم بآخر المســتجدات العلمية & ir \\
\hline$\% \Lambda \cdot . \leq$ & $\varepsilon .+r$ &. vo & تساهم (ICT) باطلاعنا على ثقافات العالم من حولنا. & ir \\
\hline$\% \Lambda \cdot . \varepsilon$ & $\varepsilon .+r$ & $1 . Y_{0}$ & التعلم باستخدام أدوات (ICT) يعمق ثقة الطالب بنفسه. & $1 \varepsilon$ \\
\hline$\% \Lambda \cdot . r$ & $\varepsilon .+1$ & $\cdot . \wedge \varepsilon$ & تسهل (ICT) عمليات التفاعل الصفي. & 10 \\
\hline$\% \Lambda \cdot . r$ & $\varepsilon .+1$ &.$\vee \wedge$ & تسهل (ICT) تنظيم الحبرات التعليمية. & 17 \\
\hline$\%$ \% $9 . \varepsilon$ & r.qV & $\cdot v 1$ & التعليم باستخدام (ICT) محبب ومشوق للمعلم. & iv \\
\hline$\% \vee q . \varepsilon$ & r.qV & 1.10 & تساهم (ICT) بتبادل الحبرات بين الطلبة والمعلمين والمدارس. & 11 \\
\hline$\% \vee v$ & r.^० & $1 . \wedge 0$ & يسهل استخدام (ICT) على المعلم الاشتر اك بالدورات العلمية. & 19 \\
\hline$\% \vee 4$ & r.^. & $\cdot . \wedge r$ & تساهم (ICT) في خلق جيل تكنولوجي أقدر على النكيف. & $r$ \\
\hline$\% \vee 0 . \varepsilon$ & r.VV & 1.10 & 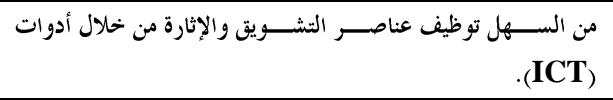 & r \\
\hline$\% \vee 0 . \varepsilon$ & r.vo &. $.7 \Lambda$ & يشجع استخدام (ICT) من عمليات التعلم الذايت ويحسنها & rr \\
\hline$\% \vee \varepsilon$ & r.v. & $1 . Y_{0}$ & تسهل (ICT) السيطرة على الموقف التعليمي بشكل فعال. & rr \\
\hline$\%$ \% r.A & 4.79 & 1.19 & يسرع إدخال (ICT) في تطور العملية التعليمية. & $r \leq$ \\
\hline$\%$ vr & T.70 &..$\wedge 9$ & التعلم والتعليم. أدوات (ICT) أكثر فاعلية من جميع الطرق الثقليدية في & ro \\
\hline$\% \vee 1 . \wedge$ & r.09 & $1 .+r$ & يجسد توظيف (ICT) فكرة أن الطالب محور العملية التعليمية. & $r y$ \\
\hline$\% \mathrm{~V}$ & r.o. & $1 . r \varepsilon$ & توفر (ICT) الوقت والجهد. & rV \\
\hline$\% 79$ & $r . \leqslant 0$ & $r \cdot+1$ & يقوي استخدام (ICT) من سيطرتنا على العملية التعليمية. & rA \\
\hline$\% 4 \wedge . \varepsilon$ & r. $\varepsilon r$ & .99 & يسهل استخدام أدوات (ICT) على المعلم حسن التخطيط لأعماله & rq \\
\hline$\%$ \%V. & r.rv & I.YY & يتحول دور المعلم باستخدام (ICT) إلى موجه ومرشد. & $r$ \\
\hline$\%$ \%० & r.ro & .99 & المدارس التي توظف (ICT) في أء ما لها أكفأ من المدارس التي & r \\
\hline $0 \%$ & r.r. & 1.00 & والبر يد الالكتروين له دور فعال في التواصــل المســتمر بين الطلبة & re \\
\hline$\%$ & r.. V &. .99 & الاعتماد الكلي على (ICT) يدعم دور المعلم القيادي في الصف. & س \\
\hline$\%$ & $r .+r$ & 1.17 & تقلل (ICT) من أعباء المعلم اليومية وأعماله الروتينية. & $r \leq$ \\
\hline$\% \diamond 9$ & Y.90 & 1.0 & يقلل توظيف (ICT) من المشتنات في الغرفة الصفية. & ro \\
\hline$\% \diamond \leq$ & r.V. & $1 . \leqslant 9$ & يقوي استخدام (ICT) من فرص الحوار بين المعلم والطالب. & 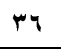 \\
\hline$\%$ \% & Y.70 & $1 .+4$ & يتفق توظيف (ICT) وطبيعة جميع المواد الدراسية. & rv \\
\hline$\%$ & r.o. & $1 . \leqslant 4$ & يسهل استخدام أدوات (ICT) الاتصال بالإدارة العليا. & rᄉ \\
\hline
\end{tabular}




\begin{tabular}{|c|c|c|c|c|}
\hline \multicolumn{2}{|c|}{ 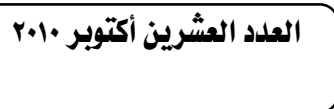 } & & & 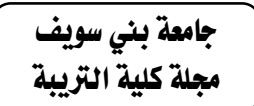 \\
\hline$\% \leqslant \Lambda$ & r.\&. & 1.19 & يقلل استخدام (ICT) من المصاريف الزائدة للمدرسة. & rq \\
\hline$\%$ \% & 1.9. & $1 .+r$ & تساهم (ICT) في مراعاة الفروق الفردية بين الطلبة. & $\varepsilon$ \\
\hline
\end{tabular}

نلاحظ من الجدول (1) أن الآراء في مجملها كانت ايجابية وبشكل متوسط حيث تر اوحت

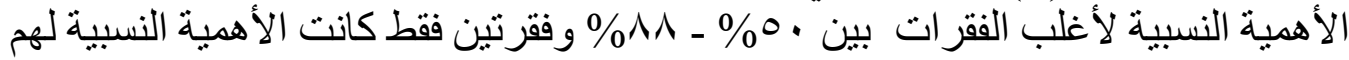

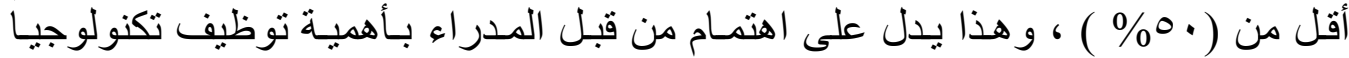

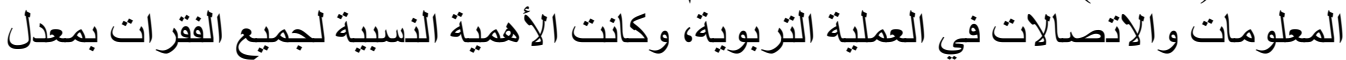

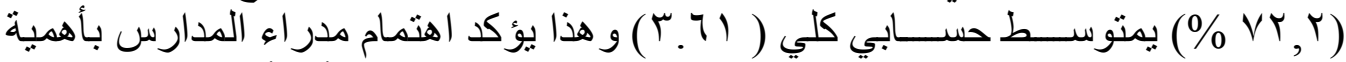

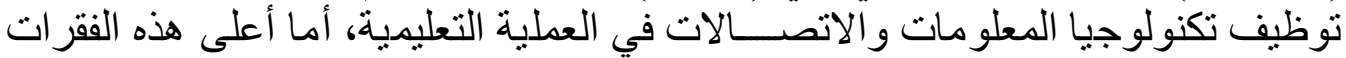

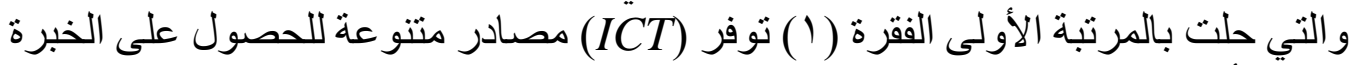

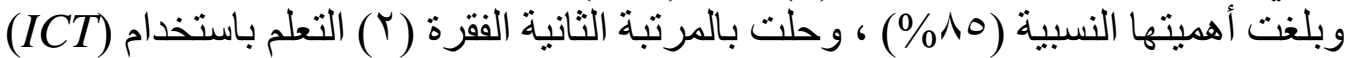

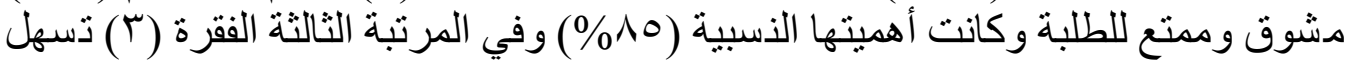
(ICT)

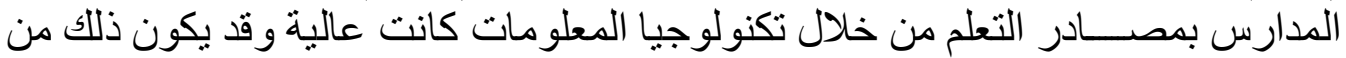

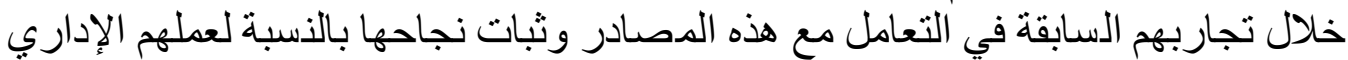

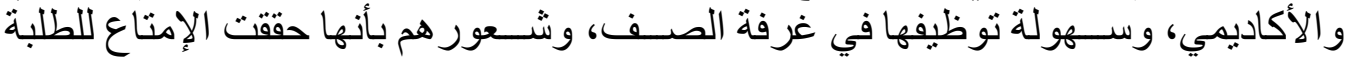

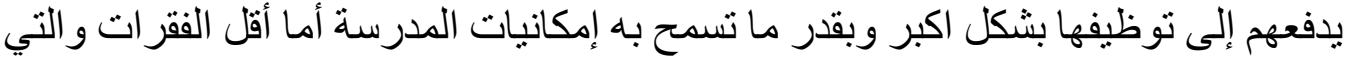

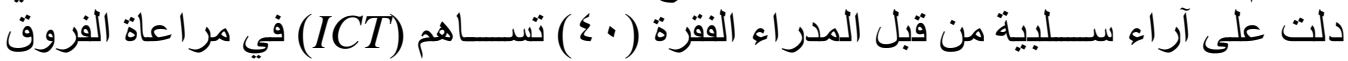

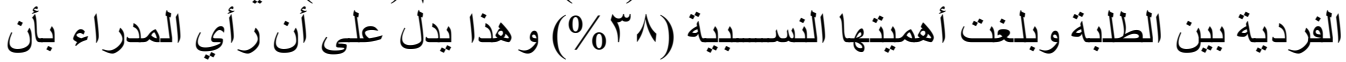

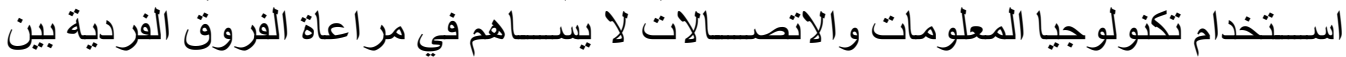

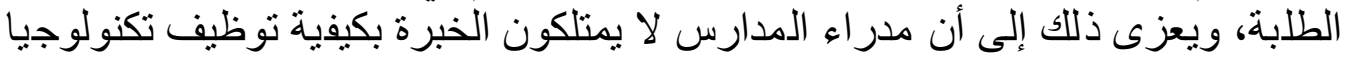

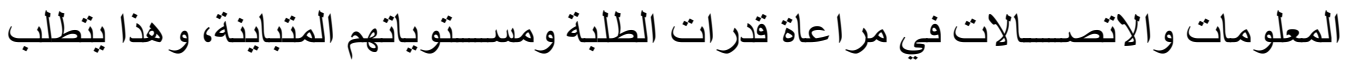

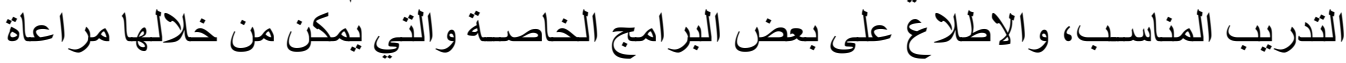

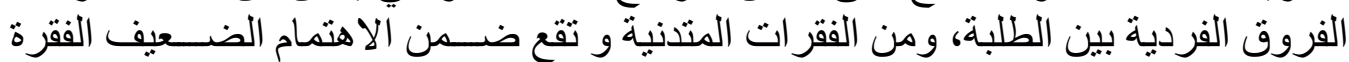

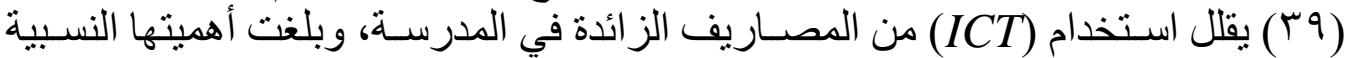

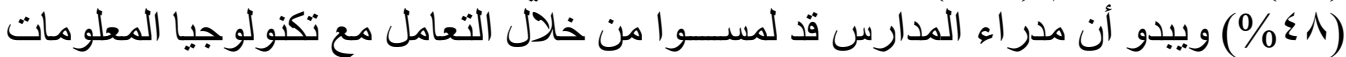

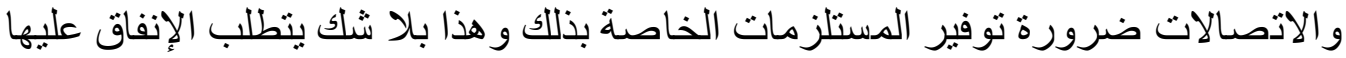

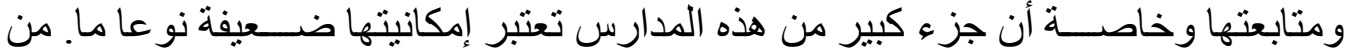

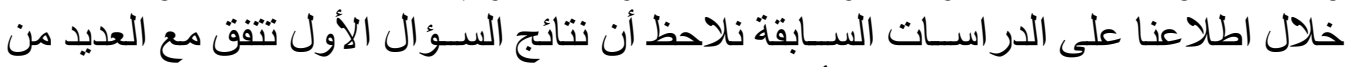

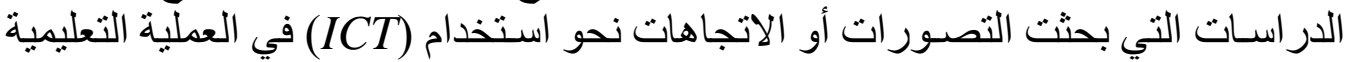

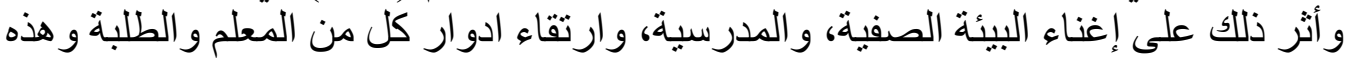

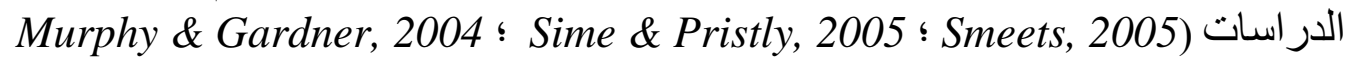
. (Mooij, 2004، Edmoneson, 2003 ؛ Hubian, 2003 ؛  


\section{r.l• • [العدد العشرين أكتوبر}

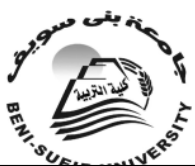

" ما أهم المعوقات التي تقلل من إمكانية توظيف تكنولوجيا المعلومات و الاتصــــالات في

للإجابة عن هذا السـؤال تمَّ حسـاب المتوسطـات الحسـابية، و الانحر افات المعيارية

و الأهمية النسبية لفقر ات الاستبانة، وهي مفصلة في الجدول(ب) التالي.

\section{جلول (Y)}

الأوساط الحسابية والأهمية النسبية لأهم المعوقات التي تحد من توظيف (ICT) في العملية التعليمية من وجهة نظر مدراء المدارس لاهم

\begin{tabular}{|c|c|c|c|c|}
\hline 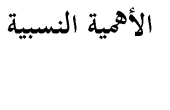 & الوسط الوسابي & الاغخر اف & 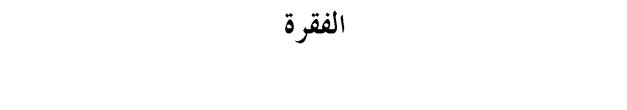 & 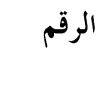 \\
\hline$\% \wedge 9 . \varepsilon$ & $\varepsilon . \varepsilon V$ & $1 .+r$ & الكهربائية، وضيق البية التحتية في المدر سة من حيث الات صالات، الطاقة & .1 \\
\hline$\% \wedge \varepsilon$ & $\varepsilon . Y$. & .91 & ازدحام الطلبة في الغرفة الصفية يعيق استخدام أدوات (ICT). &.$r$ \\
\hline$\% \wedge r . \varepsilon$ & $\varepsilon .1 Y$ & 1.1 & ضعف الطلبة في اللغة الانجليزية & r \\
\hline$\% \wedge 1.7$ & $\varepsilon . \wedge$ & $1 . r o$ & نقص الخبرة لدى الطلبة في التعامل مع أدوات (ICT). &.$\varepsilon$ \\
\hline$\% \wedge$ & $\varepsilon .0$ & I.rr & الوقت المخصص للحصة لا يكفي للثعامل مع أدوات (ICT).. & .0 \\
\hline$\% \vee 7$ & r.ی. & 1.11 & عدد أجهزة الحاسوب المربوطة مباشرة بالانترنت غير كاف. & .7 \\
\hline$\% \vee \varepsilon$ & r.v. & $\cdot . \wedge 0$ & صعوبة الاتصال مع شبكة الانترنت وبطء الشبكة &.$V$ \\
\hline$\% \vee r . \varepsilon$ & r.tr & 1.0 & 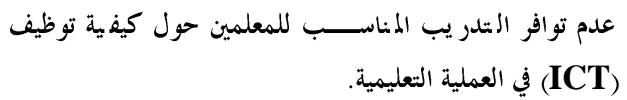 &.$\wedge$ \\
\hline$\%$ Vr & r. & $\cdot v \cdot$ & التفاعل مع أدوات (ICT) يتطلب وقتا كبيرا لتجهيزها. & .9 \\
\hline$\% \vee \cdot \Lambda$ & r.os & $1.1 \%$ & التعليمية. & .1. \\
\hline$\% \vee \cdot . \wedge$ & r.os & 1.08 & مواجهة مشاكل فنية مثل انقطاع الاتصال أثناء الحصص. & .11 \\
\hline$\%$ & r.s. &.$\wedge \mathrm{V}$ & إساءة الطلبة عملية التعامل مع معدات وأدوات (ICT). & $.1 Y$ \\
\hline$\%$ \%^. & $r . \varepsilon r$ &.$\vee \vee$ & عدم توافق المناهج الغوسبة مع الكتاب المدرسي. & سו. \\
\hline $0 \% 7 . ะ$ & r.r.r &.$\vee \vee \wedge$ & 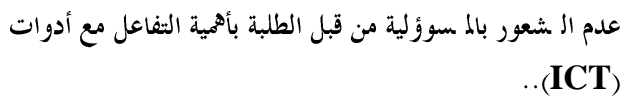 & $.1 \varepsilon$ \\
\hline ד & r.rA & $1 . \varepsilon \psi$ & $\begin{array}{r}\text { يصــعب على المعلم مثابعة جميع الطلبة أثناء التفاعل مع أدوات } \\
\text { (ICT) }\end{array}$ & .10 \\
\hline$\%$ & r.ro & 1.74 & الصيانة المتعلقة بالأجهزة غير مستمرة. & .17 \\
\hline
\end{tabular}




\begin{tabular}{|c|c|c|c|c|}
\hline \multicolumn{2}{|c|}{ 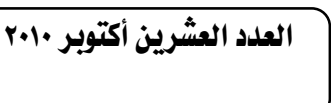 } & \multicolumn{3}{|c|}{ 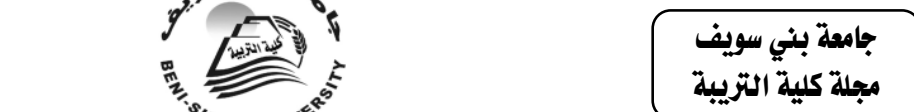 } \\
\hline$\%$ & 4.19 & I.v. & عدم كفاية الأنشطة والمهمات في المناهج الخوسبة. & $.1 \mathrm{~V}$ \\
\hline \%4r.z & r.1r & $1 . \leqslant \wedge$ & ذوات أدوات (ICT) تدعم الطالب المثميز وتضــف من أداء الطلبة & .11 \\
\hline \%ัr.ร & r.ir & $1.7 \mathrm{~V}$ & قلة عدد أجهزة الحاسوب في المدرسة. & .19 \\
\hline$\%$ \%. ร & r.qV & $\cdot \vee \vee \wedge$ & لا يوجد مشرف حاسوب لكل مختبر. &.$r$. \\
\hline$\% \diamond \wedge$ & r.q. & 1.7 & الأجهزة المتوافوة قديمة وبطيئة. &.$r_{1}$ \\
\hline$\% 0$ & r.ro & l.vr & الأهل لا يشجعون أبناءهم على التعامل مع أدوات (ICT). & .rt \\
\hline$\%$ \% & 1.9 & $1 . \mathrm{rA}$ & تضع الإدارة العقبات أمام المدرسين في التعامل مع (ICT). & r \\
\hline$\%$ \% & 1.04 & . vo & الإدارارة المدرسـية غير قادرة على توظيف (ICT) في العمليات &.$Y \varepsilon$ \\
\hline$\%$ \%^ & $1 . \varepsilon$ & $\cdot .19$ & الإدارة المدرسية لا تشجع استخدام (ICT). & ro \\
\hline
\end{tabular}

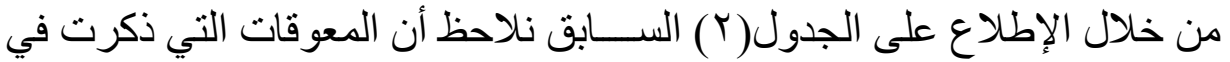

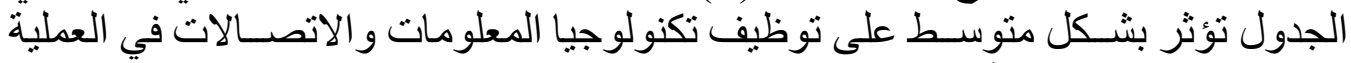

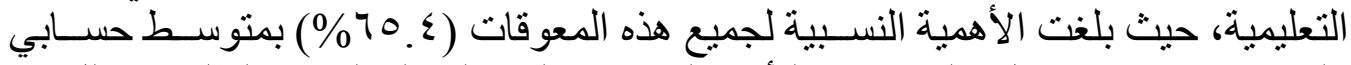

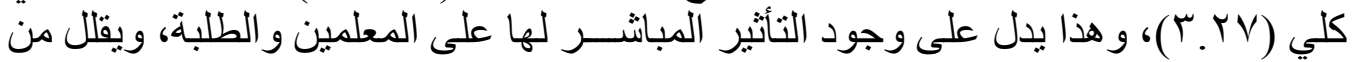

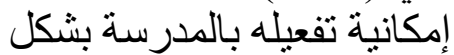

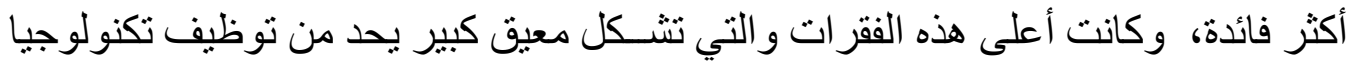

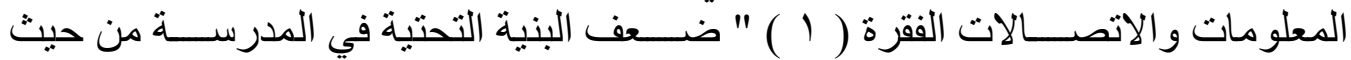

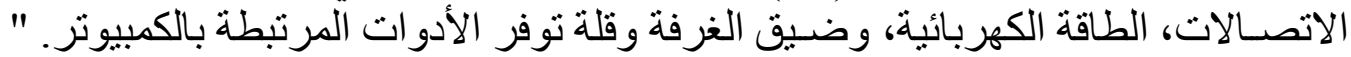

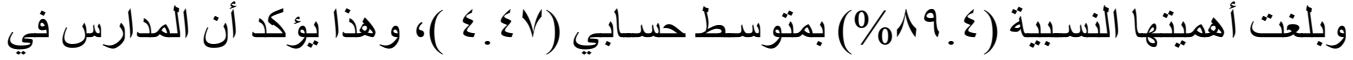

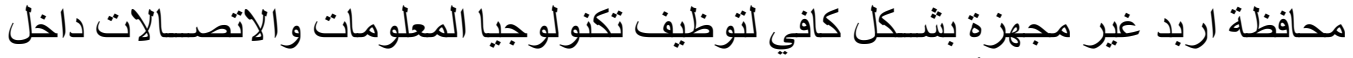

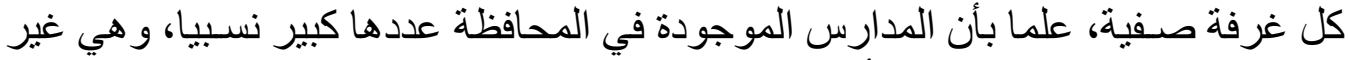

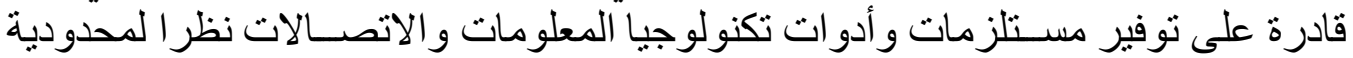

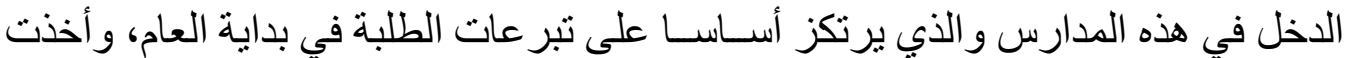

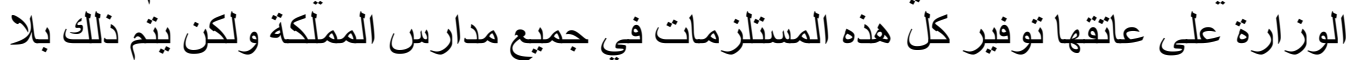

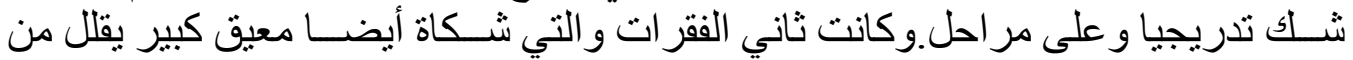

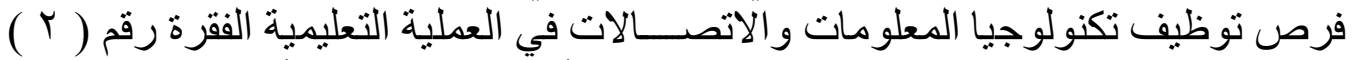

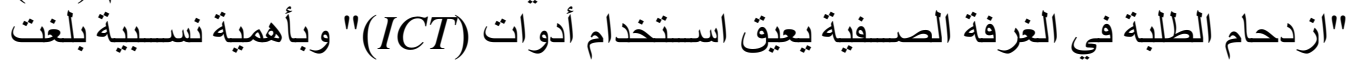

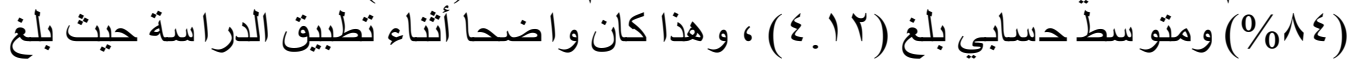

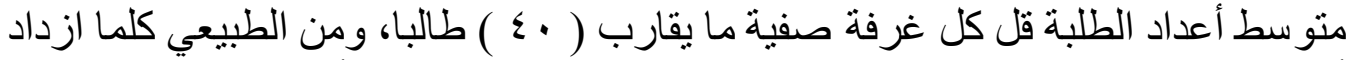

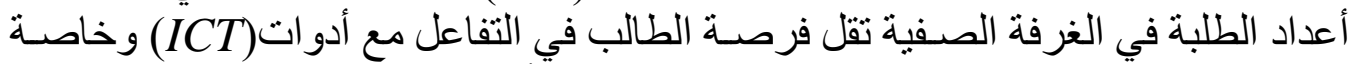

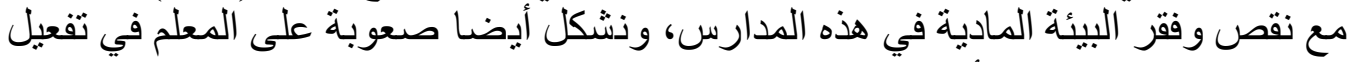

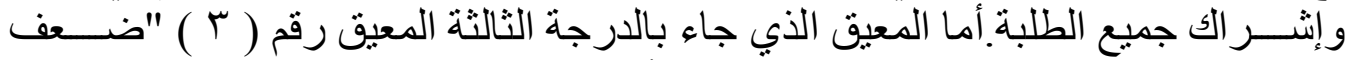

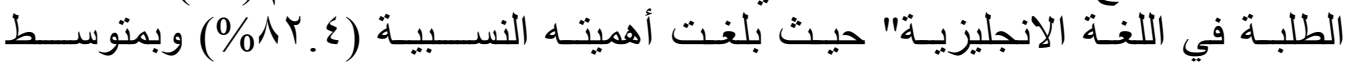


حسـابي(r ( .؟) ومن المعروف أن ضـعف الطلبة في اللغة الإنجليزية من المشـاكل العامة

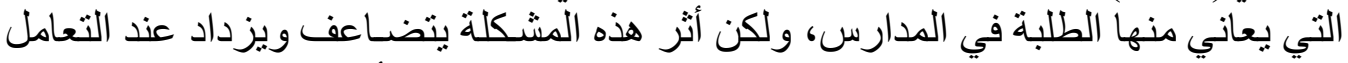

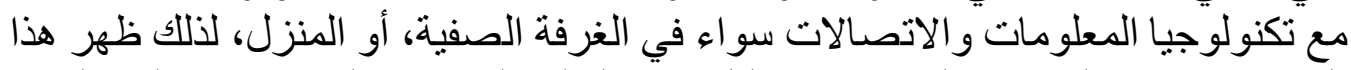

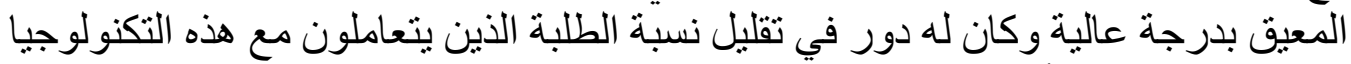

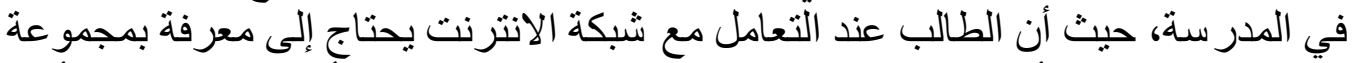

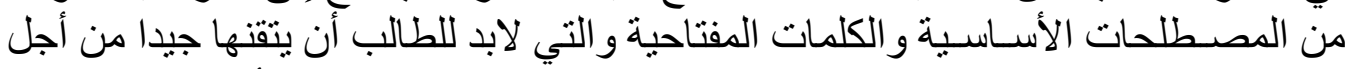

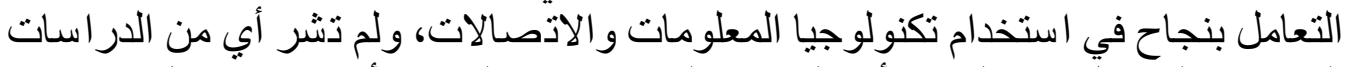

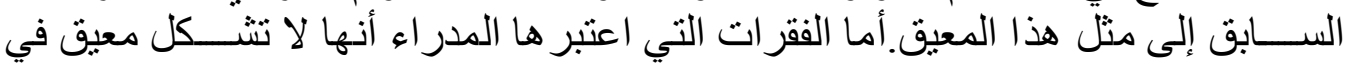

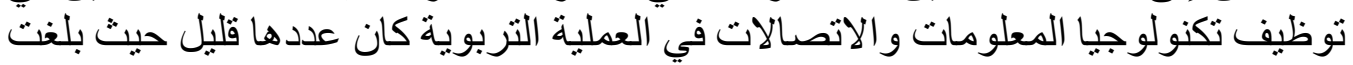

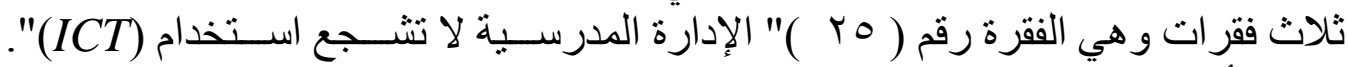

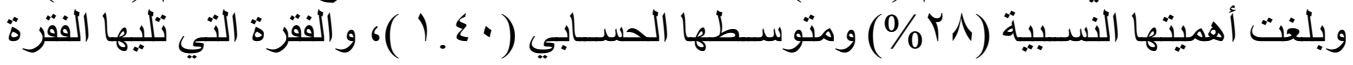

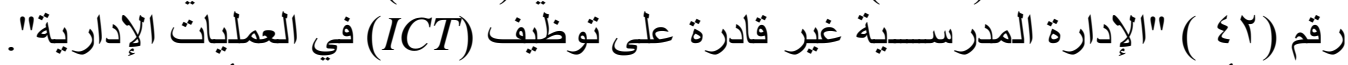

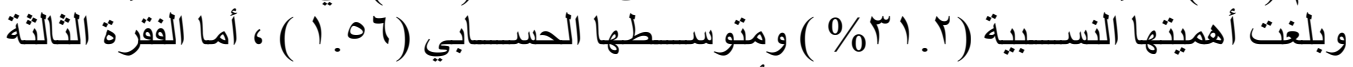

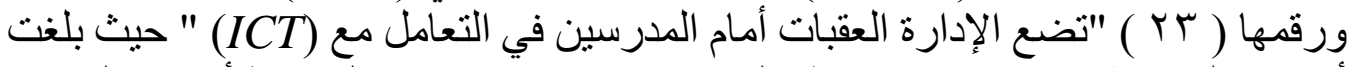

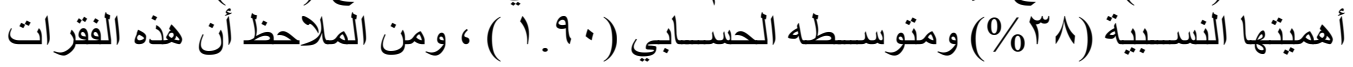

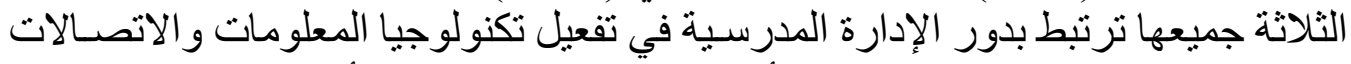

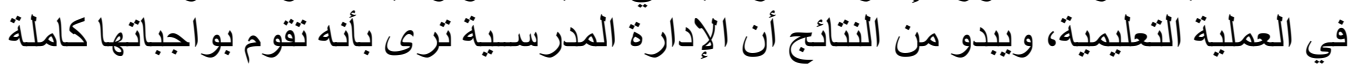

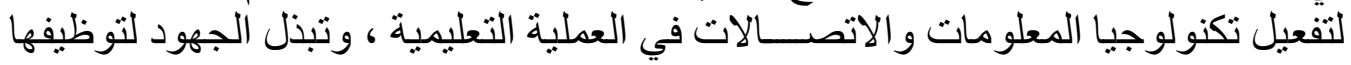

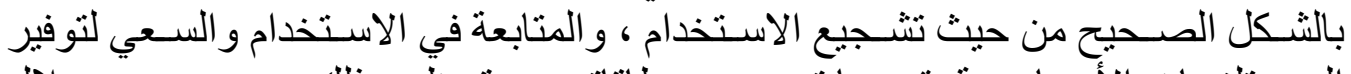

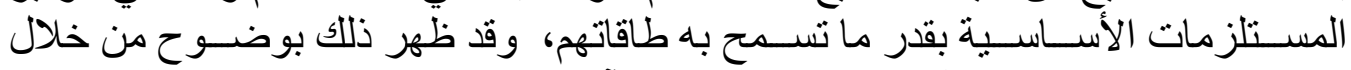

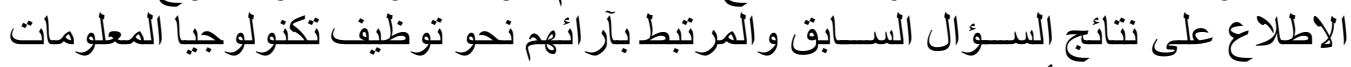

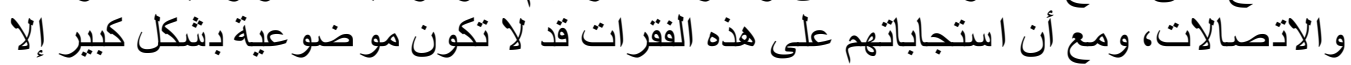

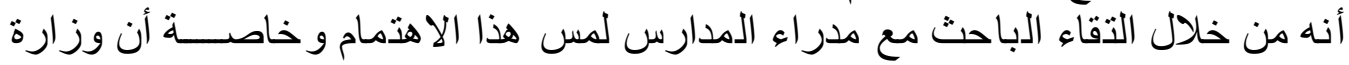

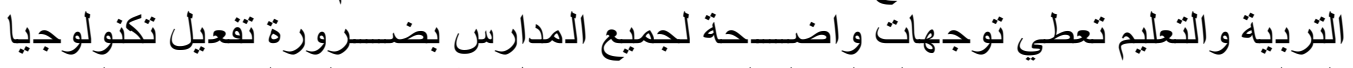

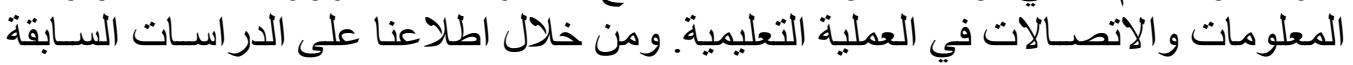

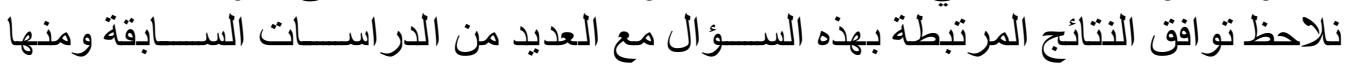

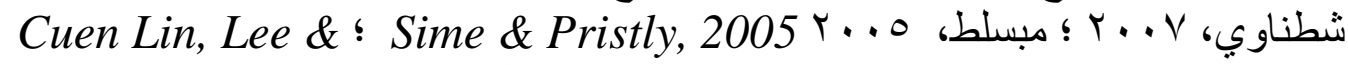
( . . . Lia \& Pratt, 2001 Yen chen, 2003; 


\section{التوصيات}

يوصي الباحث بناء على النتائج المتعلقة بهذه الدراسة بالأمور التالية:

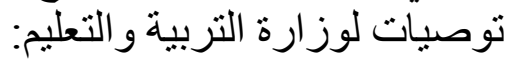

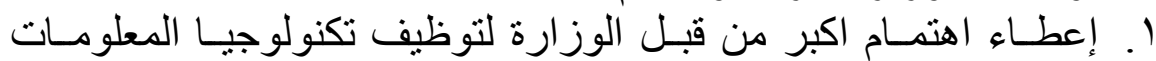

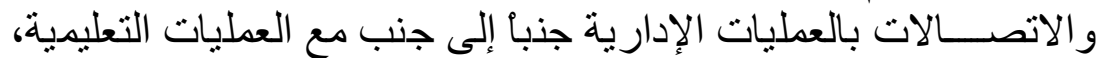

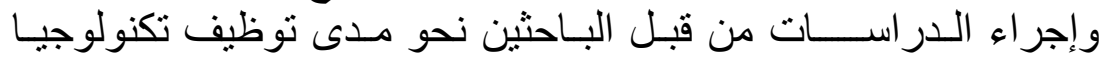

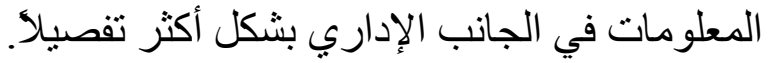

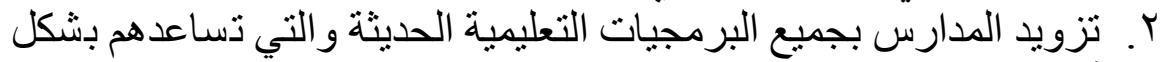

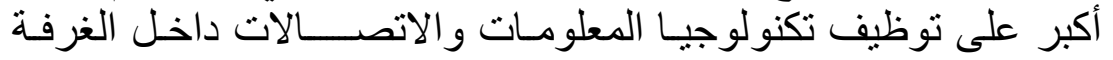
الصفية. r. توفير بذية تحتية متكاملة في جميع المدارس تســمح بتفعيل تكنولوجيا

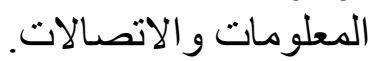
توصيات للباحثين:

1 - إجر اء در اســـات حول كيفية مر العاة الفروق الفردية الثية أثناء توظيف تكنولوجيا

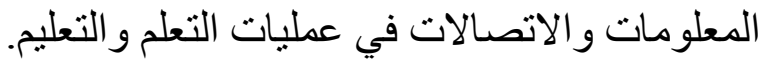

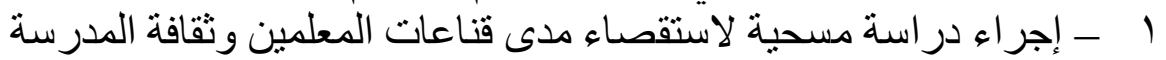

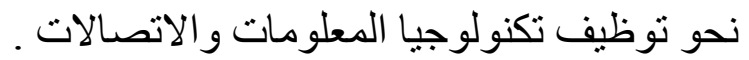

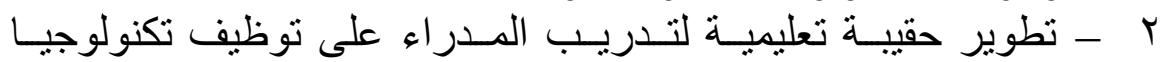

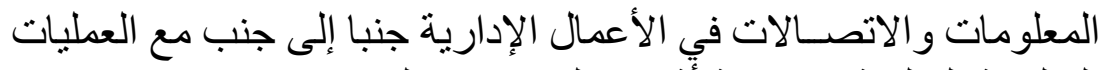
التعليمية التعلمية، ودر اسة أثنر ها على مجتمع الألى الأدراء. 


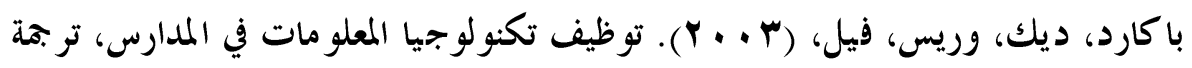
تيب توب لحذدمات التعريب والترجة، شــعبة الدراســات التربوية، القاهرة، دار الفاروق للنشر والتوزيع. جلابنة، عمر نجيب، (ع • ؟). أثر ا ستخدام برمجيات تعليمية محو سبة مبنية على أ سلوب حل المشكالت وأ سلوب التدريب والممار سة في اكت ساب طلبة الصف الثامن الأ سا سي للمهارات الأ سا سية في الريا ضيات، ر سالة ماجستير غير منشورة، جامعة اليرموك، إربد الأرون.

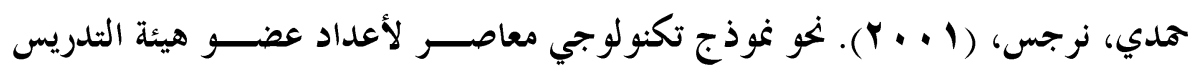

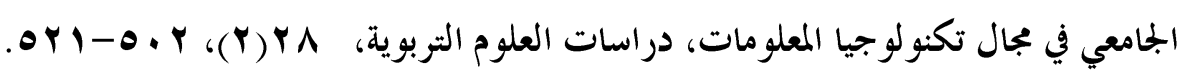

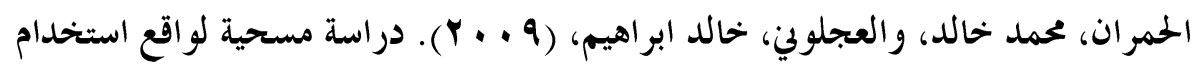
تكنولوجيا المعلومات والاتصالات في المدارس الاستكشافية في الاردن، مجلة اتحاد الجامعات

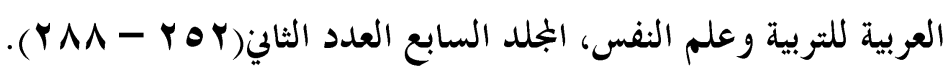
الخوري، هاين شحادة، (1 . . ( ). الن شر الالكترولي وه ستقبل الكلمة المطبوعة، العربية

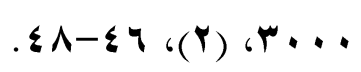

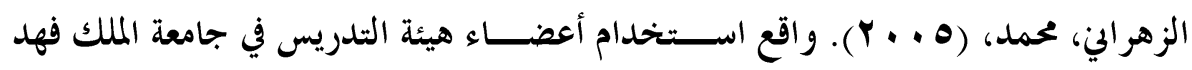
للبترول والمعادن لتكنولوجيا المعلومات والات صالات في التدريس، ر سالة ماج ستير غير منشورة، الجامعة الأردنية، عمان، الأردن. 


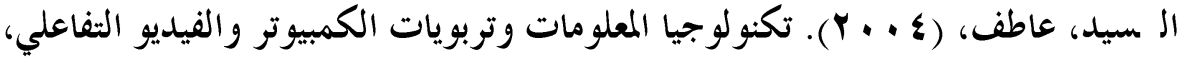

$$
\text { دار طيبة للطباعة والنشر والتوزيع. }
$$

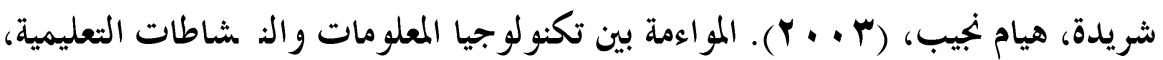

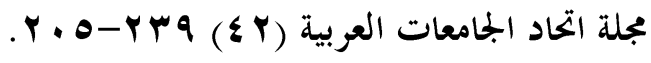

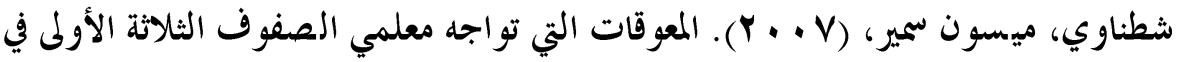

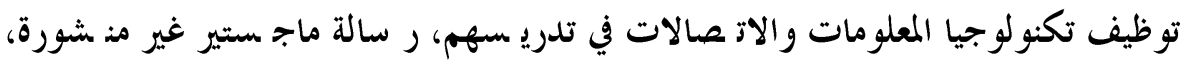

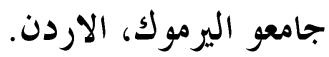

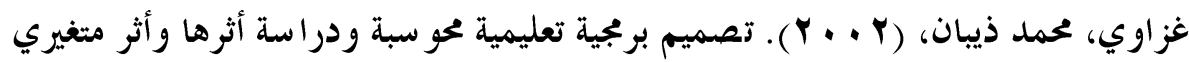

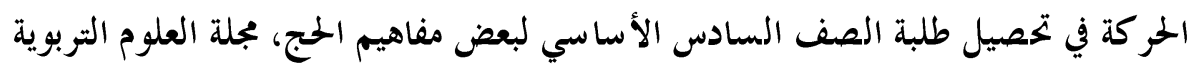

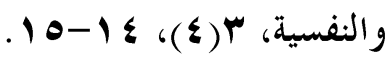

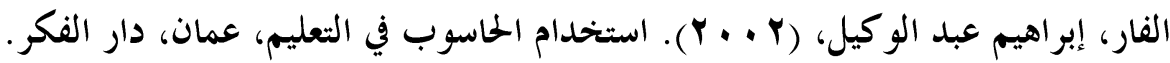

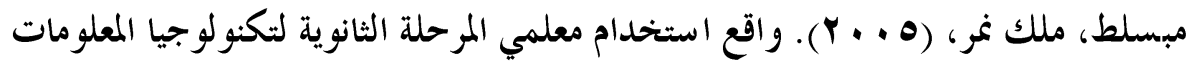

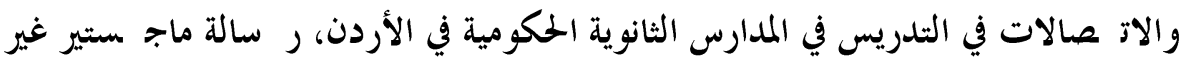
منشورة، الجمامعة الأردنية، عمان، الأردن.

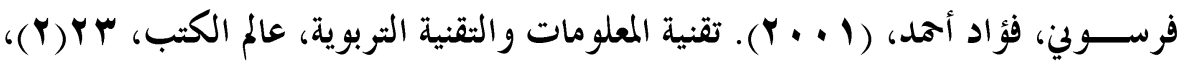
$.0 Y-r$

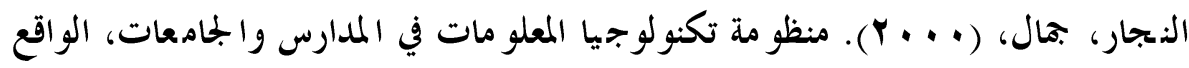
والمأمول، ورقة مقدمة في المؤتمر العلمي ال سابع لتكنولو جيا التعليم بالم شاركة مع الجمعية المصرية لتكنولوجيا التعليم، و كلية التربية بجامعة طنطا.

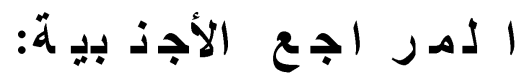

- Baylor, A. \& Ritche, D. (2002). What factors facilitate teacher skill, teacher morale, perceived student learning in technology -using classrooms? Computers \& Education, 39 (4), 395-414.

- Barry, S .(1996). Using information technology: Astudy of current and future trends. Journal of Computers Information Systems, (4), 54-60. 
- Chuen Lin, J \& Lee, C \& Yen chen, H .(2004). Exploring potential uses of ICT in chinese language arts instruction: eight teachers perspectives. Computers \& Education, 42 (2), 133-148

- Edmonson, A .(2003). What styles of computer training enhance teacher's competence and confidence to use ICT? Retrived on Line 3/7/2003. http://www.becta.org.uk/research/reports/docs/cpd-edmansan.pdf

- Galanouli, D \& Murphy, C \& Gardner, J .(2004). Teacher perception of the effectiveness of ICT- competence training. Computers \& Education. 43 (1), 63-79.

- Hubain, T .(2003). Impact of a professional project on university faculty members' perceptions and use of technology (electronic version). Journal of Social Work Education, 35 (2).

- Kompf, M .(2005). Information technology (ICT) and the education of knowledge, ahead for education. Curriculum Inquiry, 35 (2), 13-21.

- Lai, K. \& Pratt, K .(2002). Information and Communication technology (ICT) in secondary school : the role of the computer coordinator, British Journal of Educational Technology, 35(4), 461-475.

- Lakkala, M \& Legtinen, E .(2004). A case study of ICT adoption within a teacher community at a finish lower secondary school. Education, Communication \& Information, 4(1) 53-69.

- Mooij, T .(2004). Optimizing ICT effectiveness in instruction and learning: multilevel transformation theory and a pilot project in secondary school. Computers \& Education, 42 (2 ), 25- 44.

- Pich, A. \& Kim, B. (2004). Principles of ICT in education and implementation strategies in Singapore, The province of Alberta in Canada, the united kingdom, and the republic of korea. Educational Technology Systems, 32(4), 315-335.

- Renolds, D; Trehame, D. \& Tripp, H .(2000). ICT-the hopes and the reality. British Journal of Educational Technology, 34 (2), 137-150.

- Selwood, I \& Pilkngtion, R .(2005). Teacher workload: using (ICT) to release time to teach. Educational Review, 57(2), 12-63. 
- Sime, D. \& Pristly, M. (2005). Student teachers first reflections on information and communication technology and classroom learning. Journal of Computer Assisted Learning, 21(2), 13-130.

- Smeets, E .(2005). Does ICT contribute to powerful learning environments in primary education, Computers \& Education, 44(3), 343-355.

- Szabo, A. \& Hastings, N .(2000). Using ICT in the undergraduate classroom: should we replace the black- board with power point? Computers Education an Instructional Journal, 35(360), 175-187.

Zembylas, M. \& Vrasidas, C. (2005) Globalization, information and communication technologies, and the prospect of "global village": promises of inclusion 